\title{
The Impact of Investment Climate Constraints on Manufacturing Industry Performance: The Case of Dire Dawa City, Eastern Ethiopia
}

\author{
Mahider Birhanu \\ Ph.D. Candidate in College of Urban planning and Engineering, Department of Urban Planning and \\ Development, Ethiopian Civil Service University
}

\begin{abstract}
Manufacturing industry significantly has a positive effect on economic transformation through creating employment, poverty reduction, reducing regional disparities, and export product diversification. The study analyzed the investment climate constraints on manufacturing industry in Dire Dawa City, Eastern Ethiopia. The study used primary and secondary data sources. These include questionnaires, interview, and observation. The secondary data also gathered from published and unpublished sources. The target populations were operational manufacturing firms found in the study area. Out of 67 manufacturing firms, 57(85\%) of firms were taken as a sample using census study. These 57 firms selected using stratified and systematic probability sampling techniques. Different government officials and participants of in-depth interviewee were selected using purposive sampling. The data analyzed using descriptive statistics. The study has found that financial factors, institutional factors, infrastructure, social, economic, environmental, political factors, raw material availability and capacity utilization severely influencing the manufacturing industry in the study area. Thus, a good investment climate requires reaching and attaining the right economic growth and transformation. The city government should change the existing organizational structure to encourage the manufacturers and also to speed up industrialization.
\end{abstract}

Keywords: Manufacturing Industry, Investment Climate, Constraints, Dire Dawa, Ethiopia

DOI: $10.7176 /$ IEL/9-4-04

Publication date:May $31^{\text {st }} 2019$

\section{Introduction}

1.1 Background of the Study

Manufacturing industry significantly plays a crucial role in socioeconomic development to accelerate economic transformation in the national economy. As a result, the manufacturing sector makes a dynamic element of the industrial sector. The Ethiopia economy has recorded the Gross Domestic Product (GDP) growth rate of 8\% in 2015/2016. The real GDP growth was lower by 3.2\% from the base case scenario set under GTP II target rest for the year, although it was higher than the average growth estimated for Sub-Saharan Africa (NBE, 2015/2016). Manufacturing is a key sub-sector contributed about $25 \%$ to industrial output and $4.2 \%$ to real GDP during the period (MoFED, 2014/2015). World Bank report (2012) asserted that the GDP share of the private sector was only $6.9 \%$ which can be explained by several factors. Besides, out of the $11 \%$ GDP share of the industrial sector, the share of the manufacturing sector to the GDP in 2010-2014 was 4.9\% (Shiferaw, 2017). The manufacturing sector significantly contributes to the Ethiopian economy and employs about 173 thousand people in the year 2012/2013 (AACCSA, 2014). The manufacturing sector contribution to the GDP in 2012/2013 was remaining just above $4.8 \%$ for most of the above decade (World Bank, 2015). However, Ethiopia has not made a significant change in creating more jobs to shift the economy from agriculture into more productive and industrial jobs. The share of employment in the manufacturing sector has changed only slightly though these sector has been constrained by low productivity of workers and use of obsolete technologies, inadequate infrastructure, limited access to finance, limited research and development, poor institutional framework and inadequate technical and managerial skills (AACCSA, 2014). The research is relevant and serves as an empirical foundation for further research work on the issue of investment climate constraints in Dire Daw City. It will also city government and trade, industry and investment bureau need to act optimistically to solve the manufacturing firms' problems. The impact of constraints has a negative consequence in the regional as well as national economy. Different governmental offices that have a stake in the investment are not aware of what is happening to the manufacturers elsewhere. Therefore, there is a need for addressing the investment climate constraints of private investment in the manufacturing industry. Furthermore, this study will give an inspirable solution to accelerate economic growth and transformation. Despite the fact that there is no research done about investment climate constraints of private investment (manufacturing industry) particularly, in the study area. There are also limited empirical studies for well performing of the investment office. Thus, this research was conducted with the aim of filling the gaps and significant contribution to the development of manufacturing industry. 


\subsection{Justification of the Problem}

Encouraging private investment in the manufacturing sector has an effect in accelerating economic growth and transformation in terms of employment creation, innovation, knowledge and technology transfer, reduce regional disparities, product diversification, improving productivity and income, generating revenue and reducing poverty. It is widely acknowledged that a private sector-led manufacturing sector plays a key role in socio-economic transformation as a whole (Tekeba, 2018). To this end, therefore, identifying the major constraints of private investment in the manufacturing industry has critical to facilitate all the requirements need for establishing, upgrading expanding and improving firms' operational performance. According to the data found from Dire Dawa Investment office, there are 2471 private investors took investment license on agriculture, manufacturing and service sectors. Out of these, 853 private investors took investment license in the manufacturing sector with the registered capital of Birr 12,976,533,932 and expected to create jobs for 41,984 people (both permanent and temporary) starting from 1993-2017. However, there are only 67 manufacturing firms (both domestic and foreign investments) started their operations and created jobs in 7295 for people. I.e., the rate of employment creation is $17.4 \%$, though the current unemployment rate in the city is 23.9 percent in $2015 / 16$. The unemployment rate is higher next to Addis Ababa as compared to another region. The unemployment rate among female is higher than male in the Dire Dawa city. The female unemployment rate accounted for 28.5 percent and male 17.3 percent, respectively (CSA, 2014).

The remaining 786 licensed manufacturing firms are waiting for land, leave vacant land, only fence, preimplementation, and a few are under construction. Thus, the expected manufacturing licensed investment projects are far from the current actual status, i.e., only 7.8 percent of manufacturing firms are operating in the city. The remaining 92.2 percent is pre-implementation, leaving vacant land and under construction stage. These facts assert that manufacturing industries in Ethiopia and Dire Dawa, in particular, is constrained by various factors, resulting in failure to operate efficiently and effectively. This result indicates that there is a need for addressing the investment climate constraints of manufacturing industry. The administration with regard to promoting the competitiveness of the manufacturing industry is minimum. This in turn severely hampering the efforts made by manufacturing firms to accelerate industrialization.

\subsection{The objective of the Study}

1.3.1 General Objective

The general objective of the study is to identify the major investment climate constraints of manufacturing industry in Dire Dawa City, Ethiopia.

\subsubsection{Specific Objectives}

- To identify the investment climate constraints which hindering the manufacturing industries.

- To examine the impact of the weak investment climate on manufacturing performance.

\subsection{Research Questions}

- What are the investment climate constraints which hindering the manufacturing industries in Dire Dawa City?

- To what extent the investment climate constraints have an impact on manufacturing performance?

\subsection{The significance of the Study}

This research has a significant contribution to the body of knowledge in filling the policy gaps and contributes to the development of the manufacturing sector by investigating the main constraints. The study has practical significance in improving the implementation of policies or strategies or programs by indicating ways of overcoming implementation challenges. This research also has empirical significance to the existing body of knowledge by including enough written literature related to the topic, to see the gaps in scientific explanation and evidence that the researcher wants to fill.

\subsection{The scope of the Study}

The study focused only on medium and large manufacturing firms who have entered at the operational stage. The study categorized manufacturing firms into eleven sub-sectors (agro-processing, soap and detergent, textile, metal and wood works, purified mineral water, plastic products, hair food industries, sack products, foam factory, construction material manufacturing, and electronics manufacturing) in Dire Dawa, Ethiopia. The study time period covered by 1993-2017.

\subsection{Limitation of the Study}

The limitation in this research process was not severe; however, the study faced various limitations related to its thematic areas, geographic scope, methodology, respondents, resources and time. The study was conducted only on medium and large manufacturing firms, and not did micro and small scale manufacturing sectors from all 
industrial groups found in Dire Dawa City. The study also limited using concurrent triangulation mixed research design. Descriptive statistics were used to analyze the variables.

\subsection{Literature Review}

This chapter examines theoretical, empirical as well as a conceptual framework.

\subsection{Theoretical Perspectives}

Several theoretical perspectives have risen about industrial development and economic growth.

\subsubsection{Keynesian Theory}

Keynesian theory was introduced in 1936 and gives attention to the existence of independent investment behaviour in the economy. Keynes (1936) gives more emphasis regarding the aggregated demand and unemployment. Based on Asante (2000) a central feature of the Keynesian analysis is that saving and investment must be identical ex-post savings and investment decisions. They argue that investors increase to invest all savings, which results in savings equal to investment. With that insight, Keynes economies argue that aggregate demand for firms output, the rate of investment, uncertainty and other factors such as macroeconomic instability (political instability, interest rate, inflation rate, and exchange rate), socioeconomic variables (unemployment, poverty, poor infrastructure and skilled manpower) are major factors that affect the investment. Keynes (1936) describes the four possible ways to increase employment. These are: reducing frictional unemployment through improving productivity, voluntary unemployment by starting salary, increasing wagegoods industries, and enhancing the value of non-wage-goods compared to the wage-goods, linked with the expenditure. Girma (2015) stated that the Keynesian model explained that interest rate adjustments cannot be relied on saving equal to investment since the interest rate is not the major motivating force for the saving and the investment decision. Keynes introduced investment multiplier in his general theory and established the relationship between aggregate income and the rate of investment that gives marginal propensity to consume. Investment multiplier indicates that total income creates an increment of investment flows and as a result an increase in output and employment. The multiplier effect can be seen when new investment and jobs are attracted to a particular town, city or region (Bayai and Nyangara, 2013).

\subsubsection{Accelerator Theory}

The accelerator theory was introduced by Tomas Nixon (1960). Nixon (1960) explains that the relationship between output and capital stock. The accelerator theory supposes that the investment has a linear relationship relative with an output. There are three assumptions. These are: the amount of produced and investment remains constant as entirely; capital is supposed to be elastic and financial credit facilities should be easily available. The theory states that investment increases where the demand for production increase. Nixon explains that the interrelationship between the consumer's goods industries and capital goods in the factories. There is a strong positive relationship between capital goods and consumer goods. Nixon (1960) introduced the flexible accelerator model. In the accelerator model, expectations, profitability and capital costs do not have a key role in the accelerator model. This model identifies the four variables, such as output, capital, interest rate, and capacity utilization. All these four variables significantly affect the performance of private investment. This model is originated from a simple assumption about the desired fixed capital/output ratio.

\subsubsection{The Neoclassical Theory}

Neoclassical theory of investment behavior was developed by Jorgenson in 1963. Investment behavior explains the optimal capital stock accumulation. According to Jorgenson (1963), maximizing utility problems could be solved by using the production plan and resource utilization. The theory raised several assumptions for profit maximization. These are: the interest rate is constant, perfect market competition, no existence of uncertainty, the price of labour and capital are flexible. Jorgenson (1963) describes that capital stock has a positive relationship to the expected level of output and negative relation with the use of existing disposal machinery depending on interest rates, the predictable inflation rate of acquiring the new machinery and investment tax rate. This theory determines the net investment through maximizing expected profit over the current output costs and emphasizes capital stock considerably contributes, for an industrialist to take full advantage of. The neoclassical theories of Heterodox Approach argue that domestic firms lack technical and managerial knowledge, marketing access, lack of access to the global market, therefore taken initiation and sponsored by government to fill the gaps by providing adequate infrastructure, good governance and institutions, providing special investment incentives, financial incentives and easy business regulatory system and strategic location.

\subsubsection{Tobin's Q Investment Theory}

The theory was introduced by James Tobin in 1969. Tobin Q investment theory is defined as the ratio of the market value of firms to the replacement cost of their assets (Oulton, 1982). The average Q, namely the market value of existing capital to its replacement cost (Hayashi, 1982). The Q investment theory is compounded into familiar concepts of investment theory, i.e., the expected rate of return and cost of capital. The theory describes a function of investment (capital stock and profitability). The Tobin Q investment equation is derived from a 
standard Jorgenson neoclassical model of perfect competition assumption. The equations are: $\mathrm{Q}=\underline{\text { Ratio of market value of firms }}$

Substitution price of existing physical assets

The $\mathrm{Q}$ equation of the numerator indicates the ratio of the installed market price of capital, whereas the denominator shows the current substitution price of physical assets. Oulton (1981) describes that a firm investment decision depends on whether $\mathrm{Q}$ is greater than one or less than one. As $\mathrm{Q}>1$ the firm can decide to increase, replace or expand the existing capital assets through the acquisition of capital stock due to getting higher profit maximization. As $\mathrm{Q}<1$ no investment decision made by the firm, thus actual profits of a firm less than the cost of the capital stock. The higher Q equation, huge investment can be made by a firm. But as a firm actual profit below the cost of capital; a firm is better not to substitute its present fixed asset due to its ineffective performance. Furthermore, Tobin Q investment theory indicates that a firm may raise its physical assets by borrowing, selling shares or equity.

\subsubsection{Irving Fisher's Theory}

Irving Fisher theory was first published on the nature of capital and income in 1906 primarily intended to serve as a foundation for the rate of interest (1930). Fisher (1930), the investment decision of the firm an-inter temporal problem. The theory assumes that all investments are circulating, which means that all capital is used in the production process, so no capital stock exists. Further, the author states that saving brings us the nature of capital. The author claims that private investor profit maximization might be affected by different factors, such as interest rate and political instability that hinder the route of the prospect capital enlargement. Fisher (1930) argues that optimal investment decision would be made at a point, where the marginal rate of return over cost equal to the interest rate or marginal efficiency of investment equal to the marginal rate of return over cost. Fisher (1930) acknowledges the negative relationship between inflation, real income (investment) and nominal interest rate.

\subsubsection{Theories of Constraints}

The theory of constraints (TOC) is a management philosophy introduced by Eliyahu M. Goldratt in 1984 in the manufacturing contexts. The theory assumed that an organization can be controlled by operational costs, inventory and rate of the system generate. The main idea of TOC is that every manufacturing firm has at least one constraint that prevented the firms from achieving the goal of the firms to a larger performance. For this TOC develops to identify and optimize such types of constraints. There are several internal and external constraints that hindering the firms achieving the desired goals, such as capacity underutilization, shortage of skilled manpower, policies, government rules, and regulations. Marton and Paulovà (2010) stated that industries need to focus on the five steps of the theory of constraints to achieve the desired outcome. These include identifying the system constraints, decide how to exploit the constraints, subordinate everything else, alleviate the constraints, and go back to the first steps. Rahman, S. U. (1998) argued that constraints limit from achieving the higher performance of firms. On the other hand, the author stated that the existence of constraints indicates opportunities to improve its firm performance.

\subsubsection{Alfred Weber's Theory of Industrial Location}

Alfred Weber, a German economist, and industrialist. He developed Weber's Model industrial location using sociology and Geography. Alfred Weber published a theory of the location of industries in 1909. Weber's work is measured through the foundation of modern industrial location theories. Weber's assumed that manufacturing firms will decide it is a suitable industrial location due to various reasons to reduce their total product costs. The theory states the industrial location depends on the three factors, such as transportation costs, labor costs, and agglomeration factors. Weber's states that industry is located where raw material availability at least transportation cost and proximity to market. Weber has suggested a solution as location triangle. The triangle included the fixed market location and raw material sources (from raw material sources of production and from the production site to the market). The center of the triangle $(\mathrm{P})$ is the point of the least transportation cost. $\mathrm{R}$ is raw material, $\mathrm{RR}$, sources of raw materials to produce the final product and $\mathrm{M}$ is a market.

\subsection{Empirical Literature}

Matar and Eneizan (2018) conducted a study on the determinants of financial performance in industrial firms in Jordan. The time period covered from 2005-2015. The study used secondary data of 23 industrial firms' financial statement analysis (balance sheet and income statement). SPSS and E-views software packages employed for regression analysis. The findings showed that liquidity, profitability, and revenues had a positive association with return on investment, but firm size and leverage had a negative impact on it. In general, all variables had an impact on the financial performance of industrial firms.

Kumarasamy and Singh (2018) conducted a study on access to finance, financial development and firm ability to export in Asia Pacific countries. The study was used World Bank Enterprise Survey Data (WBES). The result indicated that good access to formal finance improved the manufacturing firms' performance and could get opportunities to enter into the export market. 
Oguntoke, O., et al. (2018) in their study the impact of cement factory operations on air quality and human health concluded that, cement factory's, mainly characterized by greenhouse gas emission, nitrogen oxide, sulfur oxides, and carbon monoxides had a negative impact on the environment and human respiratory health and skin infections. Therefore, the cement factory had a negative impact on the environment and human health. The study also suggested that it was very critical to environmental law on emissions that would protect the environment and human life.

Cohen and Tubb (2018) wrote that, the impact of environmental regulation on firm and country competitiveness. The study found that environmental regulation had a positive effect on competitiveness, but it needs to have flexible environmental regulations that induce innovation.

Zariyawati, M. A., et al. (2017) examined a study on working capital management and firm performance of small and large firms in Malaysia. The time period covered from 2009-2013. OLS used to analyze the panel data. The result showed that working capital had a positive effect on firm performance.

Worika and Umofia (2017) examined a study on the impact of infrastructural development in Nigeria. The time period was from 1990-2015. Ordinal least square regression method used to analyze the time series data. The study sets an indicator for industrial sector performance and infrastructural development. Industrial sector performance was an industrial value added (GDP) where electricity consumption, gross capital formation, government expenditure on transport and communication for infrastructure development. So, the findings indicated that electric power consumption had a positive impact, but insignificant for industry value-added. Government expenditure on transport and communication had a negative and significant impact on industry value-added. The study recommended that it needs properly to maintain and build the infrastructure to enhance the large volume of industrial productivity.

Al-Tit (2017) using a sample of 93 manufacturing firms found that organizational culture and supply chain management was a significant determinant of manufacturing firms' performance in Jordan.

WAMIORI, G. M., et al. (2016) conducted a study on the effect of access to finance on the financial performance of manufacturing firms in Kenya. The study was utilized both stratified and simple random sampling techniques. Factor analysis method was used. The finding showed that access to finance had a positive impact on manufacturing firm performance and suggested that policymakers need to make better policies on improving financial performance.

Obokoh and Goldman (2016) analyzed that infrastructure deficiency and the performance of manufacturing firms in Nigeria. The study followed a longitudinal approach using the semi-structured interview. The time period was 2007-2011. The result showed that the shortage of infrastructure had a negative and significant relationship with the performance of manufacturing firms, especially electric power supply.

Nwandu (2016) conducted a study on the impact of rising interest rate on the performance of the manufacturing sector in Nigeria. The time period covered by 1981-2015. The study adopted the ex-post factor research design and used ordinary least squares after ensuring the stationary data set properties. The finding showed that the high-interest rate had an adverse impact on the contribution of the manufacturing sector to GDP as well as capacity utilization. The study recommended that the government should manage interest rate for enhancing economic growth.

Tasneem, F., et al. (2016) analyzed the impact of environmental reporting on firm performance. The study adopted a descriptive and explanatory research design on the basis of secondary data collection. The result depicted that greenhouse gas emission, water consumption, and waste disposal had an impact on the firm's performance.

Pierre and Wondweson (2016) stated that the main sources of environmental pollution from agricultural activities, industrial effluents, municipal wastes, domestic wastes, fuelwood burning, and vehicle emissions. Environmental pollution damages the resources as a result of degradation or pollution. The main pollutant manufacturing industries are leather, textile, dairy, beverages and food processing, and cement factory. The industrial sector releases greenhouse gas emission.

Eckelman and Sherman (2016) analyzed the environmental impacts of the health care system and the effects on public health in the USA. The authors found that environmental impacts had a significant association with health care practices, thus these findings highlighted that effects should measure, mitigate, educate, and improve the environmental impacts through waste reduction and energy savings.

In a study conducted by Helhel (2015), a comparative analysis of the financial performance of foreign and domestic banks in Georgia. The time period covered from 2009 to 2013. The author stated that manufacturing firms highly exposed to an exchange rate that can be determined by the export ration and assets. The study concluded that the export of manufacturing firms and the exchange rate had a negative relationship, but no relationship with firms' age. This is as expected, that exporting firms, especially large manufacturing firms tend to participate in foreign markets.

Reppen (2015) conducted a study on infrastructure is a binding constraint on African light-manufacturing firms. Ordinal least squares method was used for regression analysis. The findings indicated that infrastructure 
had a significant positive relationship with manufacturing firms.

Hailu and Debele (2015) investigated the effect of monetary policy on private investment in Ethiopia. The study time period was from 1975-2011. ADRL Co integration approach was employed. The study identified six variables, such as the real exchange rate, domestic credit to the private sector, real GDP, real interest rate, inflation and government expenditure (public investment) determined as a control variable. The finding of this study showed that private investment had a positive effect in the short run to public investment, money supply, and output, but it had a negative effect on the real exchange rate in line with macro-economic theory. In the long run, the study found that private investment had a significant and positive effect on public investment, real GDP and foreign cash inflows, but real interest rate has a negative impact on private investment. Finally, the authors concluded that monetary policy and private investment had a strong relationship and positive effect in the long run and short run, but interest rate and inflation rate had a negative impact on the performance of the firms.

Latake, P. T., et al. (2015) had published papers on the greenhouse effect and its impacts on the environment. They discussed about sources and their impacts on the environment (economic, agricultural, aqua systems, hydrological, and global warming). Based on these, the findings showed that the activities related to power generation and energy consumption had a significant relationship with greenhouse gas emission which is the main source of global warming.

Mark and Nwaiwu (2015) asserted that the political environment had significantly a negative impact on business performance of global companies. Recent empirical studies

Adugna, A. A., et al. (2015) stated that financial access, marketing, infrastructure facilities, incentive provision, land provision process and getting required land size, and bureaucracy hinder the manufacturing sector in Tigray, Northern Ethiopia. The authors recommended that the government should create favourable conditions in motivating private investors.

Addis Ababa Chamber of Commerce and Sectorial Association (2015) conducted a study on an overview of the manufacturing industry in Ethiopia. The study showed that there are various challenges hinder the manufacturing firms, such as environmental change had a negative impact on agricultural products, lack of entrepreneurial skills, globalization, contraband/ illegal trade, lack of adequate resource potentials, and poor land management system.

Eze and Ogiji (2014) examined the impact of fiscal policy on the manufacturing sector output in Nigeria. The study used graphs, co-integration and error correction model for the time frame 1990-2010. The study used secondary data obtained from the CBN Statistical Bulletin and Academic Journals. The authors identified the manufacturing sector output as dependent variables, where government expenditure and government tax revenue are independent variables. The result showed that government tax revenue had a negative impact on the manufacturing sector, where government expenditure had a positive effect on the manufacturing sector output growth. Based on findings, the authors recommended towards promoting the impact of fiscal policy on manufacturing sector output, which leads to expansionary policies to enhance growth and development. The fiscal policies should give priority towards manufacturing sectors by increasing the budget allocation and proper implementation to enhance aggregate spending in the economy.

Moses, K. et al. (2014) conducted a study on the effect of the manufacturing industry on the environment in the Ashante of Ghana. The descriptive statistics were employed in the study. Both quantitative and qualitative data were analyzed. The study revealed that air and water pollution was the most leading factors of pollution in the area. There was also a close relationship between various types of pollution and diseases. Recent empirical studies Hashem and Irshaidat (2014) conducted in Jordan, found that political and legal factor had a negative effect on industrial export performance.

Wangwe, S, et al., (2014) conducted a study on the constraints and challenges facing the emerging manufacturing firms. The result showed that technical problems (lack of reliable energy, outdated machine and equipment, inadequate technical knowledge, and skills, lacks of sophisticated information and communication, technology), administrative matters (rules and regulation, poor enforcement of laws, complex legal and institutional framework, negative attitudes against consumption of locally produced goods, employee compensation, and work morale, poor customer services, and management challenges), market challenges (poor transport infrastructure), financial barriers (high cost of working capital, high cost of raw materials and other inputs, high energy costs and depreciation of nominal exchange rates) and policy issues (too many regulations, waste disposal challenges, nuisance taxes, weakness in the firm-specific policies, coherence of trade and related policies for the development of the management sector) significantly influencing on manufacturing firms.

Lotfalipour, M. R., et al. (2013) analyzed the exchange rate impact on the manufacturing sectors in Iran. The time period covered from 1995-2009. The study used the panel data to examine the impact of exchange rate fluctuation on manufacturing firms. So, the findings showed that there was a significant negative relationship between exchange rate fluctuations and manufacturing investment.

Azam and Ahmad (2013) assessed the effects of corruption on foreign direct investment inflows relatively long time period, 1985-2011. The authors found that corruption adversely affects foreign direct investment 
inflows. The study suggested creating a good investment climate was critical for attracting more foreign direct investment.

Ihugba, O. A., et al. (2013) asserted that private enterprises were the spine of overall socioeconomic development, employment creation, improving living standard for people, reducing rural-urban migration, reduction of import machinery and equipment, which leads to a social change in the country. The authors found that unnecessary bureaucratic procedure, corruption, unstable government policy framework, the shortage of credit facilities, inadequate infrastructure, poor planning; poor product and services and double taxation a significant impact on private enterprises.

IEG, S. O. (2013) noted that a good investment climate. The study indicated that good investment climate includes the macroeconomic stability, good governance (reduction of bureaucracy, adequate financial provision, control of crime and corruption, regulatory quality, and the effectiveness of public service, quality of labour forces, and quality of infrastructure). In order to grow, enterprises need capital to invest in the specified potential sectors to increase their productive capacity and to be competent at a global and local market. For firms to invest, the risk-adjusted rate of return on capital (after tax) needs to be greater than the cost of borrowing the capital or the opportunity cost of using their own capital elsewhere.

Duru (2012) in his study of the new challenges facing industrial policy in Nigeria found that globalization and global sharing had a negative impact on industrial policy. The author suggested that industrial policy requires more research to tackle the lack of inclusiveness, relating incentives with penalties, ensuring government accountability, reducing information gaps and minimizing the risk of rent-seeking.

Osemeke (2011) wrote that, the challenges and prospects of the private sector in Nigeria. The author found that inadequate finance provision, shortage of capital markets, unpredictable and weak policy framework, inadequate and deteriorating infrastructures support (electricity, water, road); low consumer purchasing power, poor/low quality products, high cost of equipment and working capital, multiple levies and taxes; inefficiencies in customs and port administration; dumping of cheap products on the market, an irregular pattern of exemption to consumption taxes and import tariffs, complexities in the legal framework; high import dependency; underprivileged administration performance and low entrepreneurial skills negatively affect private sectors. Thus, the government should harmonize different policy environment, ensure and create a conducive environment for private sectors.

Minetti and Zhu (2011) conducted a study on credit constraints and firm export in Italy. The time period was from 1998-2005. The study found that credit was a major bottleneck to export large manufacturing firms' product that highly depends on external debt.

Fiestas and Sinha (2011) revealed the constraints to private investment in the poorest developing countries, particularly Sub-Saharan Africa and South Asia. The author identified the five major investment climate constraints that increase the risk and cost of investment, depress returns or prevent the firms. This includes the macro environment constraints (macro level stability, crime, and corruption); institutional constraints (business regulations, legal and tax systems); finance constraints (access to and cost of finance); infrastructure constraints (electricity, water and roads); micro-level constraints (technology transfer and quality of management).

World Bank Group (2005) asserted a comparative study on a good investment climate. The study stated that a good investment climate provides opportunities and incentives for firms from microenterprises to multinationals to invest productively, create jobs, and expand, thus it plays a central role in growth and poverty reduction. The good investment climate is essential to create more inclusive jobs for young people, balanced, and peaceful world. A good investment climate also has an impact on the productivity of investment and hence it is a key to sustained economic growth and poverty reduction. Therefore, private investment in manufacturing firms and investment climate has a significant relationship to economic growth and transformation, which may enhance employment, high productivity, quality infrastructure and quality life for all residents.

\subsection{Research Methodology \\ 3.1 Introduction}

In this section presents research philosophy, research design, data sources and method of data collection, sampling procedure, and data analysis.

\subsection{Research Philosophy}

Research philosophy is the development and nature of knowledge. It can be considered as the way of observing the world to construct specific research strategies and methods. Creswell (2014) argued that researchers seek to identify their philosophical ideas from a world point of view while choosing a research approach. There are three philosophical ideas such as ontologies, epistemologies, and paradigms. According to Creswell (2014), the world point of views is classified into four groups: post-positivism, constructivism, transformative and pragmatism. Taking into account this research adopted the pragmatism philosophical point of view in order to yield better research outcomes. According to Kalolo (2015), pragmatism is a practical approach that helps to find a solution 
for existing problems.

\subsection{Research Design}

Research methodology is a way to systematically to solve the research problem (Kothari, 2004). As research adopted the pragmatist world-view, this research employed a mixed research method (both quantitative and qualitative approaches) thus pragmatism is a cornerstone for mixed research method studies. A mixed method design is characterized by a combination of at least one qualitative and one quantitative research component (Schoonen\& Johnson, 2017). A mixed research method involves collecting, analyzing, and in some way integrating both quantitative and qualitative data in a single project (Leavy, 2017). Sharing the idea of scholars concerning the integration of both quantitative and qualitative approaches, the researcher has been employed concurrent triangulation mixed research design or convergent parallel in this study that helped me to collect, analyze, compare and contrast both quantitative and qualitative data at the same time i.e., concurrent timing. The two data approaches had equal weight and play an equally vital role in addressing the research questions

\subsection{Data Source and Method of Data Collection}

The primary data are collected a fresh and for the first time, and thus happen to be original in character (Kothari, 2004). The secondary data collected by someone else and which have been passed through the statistical process (Ibid). Both quantitative and qualitative data were collected. The qualitative data was collected from survey instrument open-ended questions, and interview that is expected to support the analysis of the survey questionnaires with governmental office reports and observations. This study used both published and unpublished sources including, progress reports, journals, books, research works, and various documents. Windle (2010) stated that secondary data sources are vital for describing, explaining and interpreting primary sources using various materials, studies, and records of events.

\subsection{Population and Sampling Technique 3.5.1 Population}

For this research, the total populations for this study are licensed investors that are involved in the manufacturing sector. However, the target population is those which entered the operational stage, key informants and concerned governmental offices in the Dire Dawa city.

\subsubsection{Sample Procedure}

The sample size was decided to use from urban kebeles, thus most of the manufacturing firms found in the urban area. Currently, there are 67 manufacturing industries operating in the city, though 853 investment projects took investment license in manufacturing sectors. The current operational manufacturing firms are agro-processing, soap and detergent, textile, wood and metal work, purified mineral waters, hair food factories, plastic factories, construction material manufacturing, electronics manufacturing plant, and sack factory. In order to achieve the stated objective, the study used census study. Thus, the census study helps to collect better data from the population. Al-Subaihi (2003) asserted that if the population that the researcher wishes to study is small $(<200)$, the researcher should measure the interest variables for every subject in the population. The sample of 57 operational manufacturing industries selected using stratified and systematic sampling technique. For qualitative data, the researcher used purposive nonprobability sampling to select 20 key informants for an interview and 10 manufacturing firms for personal observation. From purposive nonprobability sampling, the researcher employed maximum variation (heterogeneous) sampling to address the research questions from various angles. Thus, it helps to get closely observable facts from different participants. In general, both quantitative and qualitative data employed from different sources as a total sample size of 87.

\subsection{Method of Data Analysis}

For quantitative, the data were analyzed using Statistical Package for the Social Science (SPSS.22) to generate various descriptive statistics in terms of frequencies, percentage, graphs, and pie-charts. The data also analyzed using a measure of central tendency and measure of variability: mode, median, range, and quartile. For qualitative, the researcher prepared in-depth interview questions to different interviewees. The raw data had been collected by using recording, writing field notes and then convert into word forms. The collected qualitative data were analyzed using narrative analysis. The secondary data also analyzed using document review. Finally, the end result of both quantitative and qualitative data was integrated using the convergence model to draw a conclusion and recommendation.

\subsection{Reliability and Validity}

\subsubsection{Instrument Reliability}

The researcher checked the reliability by preparing suitable data instruments to address all research questions. For these, the researcher placed clear and unambiguous instructions, consigned proper and clear indicators for 
each variable, and pre-tested some questions by taking certain manufacturing firms. In qualitative, the researcher ensured the reliability using dependability that the data verified the quality of the research by examining the raw data and reducing redundant the data. Creswell (2009) states that reliability instrument measures the degree of consistency.

\subsubsection{Instrument Validity}

The study ensured the data using content, internal and external validity. For content validity, the researcher checked a detail the explanation of research question, examined vague information, and checked the subject matter that adequately covered. Six operational manufacturing firms were selected randomly to validate the instrument. The researcher adequately reviewed empirical studies in line with the study objectives and the research findings. The researcher prepared in-depth interview questions and asked 20 key informants. Besides, the researcher was adopted triangulation mixed research design, statistical tools, observing at the research site and reduce the non-response rate to validate the instruments. The study adopted a suitable data collection method, appropriate criteria for the mixed data model, the time period for data collection, and triangulated the existing theories and previous studies with the findings.

\section{Result and Discussion}

\subsection{Introduction}

Fifty-seven questionnaires were distributed for the 11 manufacturing sub-sectors. The whole questionnaires were successfully completed. This represents the response rate of $100 \%$.

\subsection{Research Question One: Investment Climate Constraints Results 4.2.1 Financial Factors}

As the table 4.1 below indicates $44(77.2 \%)$ of respondents asserts that manufacturing firms faced lack of access to finance, but $12(22 \%)$ of them disagreed and $1(1.8 \%)$ do not have a comment on the problem. The result proves that the mean score of the median value for access to finance is larger than the theoretical score of 3 . However, the midpoint value (3) also confirm that the fact lies in the mid in the scale extending from "strongly disagree" to the "strongly agree" which indicate that the majority of manufacturing firms were faced lack of access to finance. Besides, $46(80.7 \%)$ of manufacturers that agreed on the shortage of working capital severely affect the manufacturing firms albeit $10(17.5 \%)$ of an industrialist disagreed and $1(1.8 \%)$ reserved from giving answers. The middle value (3) which explain the fact that the firms affected by the shortage of working capital. Regarding high collateral requirement, 41 (71.9\%) was believed that influencing the firms while $15(26.3 \%)$ of respondents does not have the same opinion on the problem and $1(1.8 \%)$ was impartial from providing the responses.

Results of descriptive statistics show that the median value of high collateral requirement is $4.46(80.7 \%)$ of respondent decided that there was a problem of delay in loan delivery, while $10(17.5 \%)$ of them oppose the provided questions and only $1(1.8 \%)$ unbiased on this responses. The middle value of loan delivery procedure is 4. The majority 54(94.7\%) of respondents were confirmed that there was a shortage of foreign currency while $3(5.3 \%)$ of those who differ their responses. The middle value of foreign currency is 5 . Similarly, $49(86 \%)$ of respondents highly indicate that there was instability of foreign exchange rate, but $8(14 \%)$ of them responses to the option show a discrepancy. The median values for the foreign exchange rate are 4 . This result proposes that financial factors (access to finance, shortage of working capital, high collateral requirement, and complexity of loan delivery procedure, shortage of foreign currency and instability of exchange rate) are a major bottleneck for the manufacturing industries. Thus, it needs requires creating a favorable business environment in the study area.

Respondents were asked about the financial constraints. The results indicate that various financial factors affecting their firms: lack of access to external finance, inefficient of loan approval, managerial agency problem because of high transaction costs, the government policies and bank loan delivery system is not the same because of various bureaucratic red tape, lack of quality feasible studies and financial resource limitation in the financial institutions are the basic problems of manufacturing firms in order to perform business activities.

The interview with firm owners revealed that the shortage of access to financial credit facilities, hampering the manufacturing firms from expanding, upgrading, and utilizing its full capacity. For that reason, their efficiency was not sufficiently performed and qualified. Furthermore, the lack of access to capital markets was also the main reason for their capacity underutilization. Shortage of foreign currency and instability of foreign exchange rate was also cited as a difficulty encountered by manufacturing firms. Thus, manufacturing industries were forced to operate from their previous status, which in fact limited their growth due to financial constraints. Similarly, the interview with governmental officials also agreed that there is a problem the existence of the financial constraints and access to credit facilities in the study area. Hence, the result is consistent with an interviews found that the manufacturing firms significantly influenced by financial factors. Table 4.1 shows the percentage of financial factors. 
Table 4.1: Financial Factors

\begin{tabular}{|l|l|l|l|l|l|r|}
\hline Responses & LACC & SWOC & HCOLLAT & CLODELI & SFOXC & INSEXR \\
\hline Strongly agree & $17(29.8 \%)$ & $18(31.6 \%)$ & $10(17.5 \%)$ & $21(36.8 \%)$ & $44(77.2 \%)$ & $23(40.4 \%)$ \\
\hline Agree & $27(47.4 \%)$ & $28(49.1 \%)$ & $31(54.4 \%)$ & $25(43.9 \%)$ & $10(17.5 \%)$ & $26(45.6 \%)$ \\
\hline Disagree & $8(14 \%)$ & $8(14 \%)$ & $11(19.3 \%)$ & $8(14 \%)$ & $3(5.3 \%)$ & $8(14 \%)$ \\
\hline Strongly disagree & $4(7 \%)$ & $2(3.5 \%)$ & $4(7 \%)$ & $2(3.7 \%)$ & -- & - \\
\hline Undecided & $1(1.8 \%)$ & $1(1.8 \%)$ & $1(1.8 \%)$ & $1(1.8 \%)$ & - & - \\
\hline Median & 4 & 4 & 4 & 4 & 4 & 4 \\
\hline $\begin{array}{l}\text { Upper } \\
\text { Quartile }\end{array}$ & 5 & 5 & 4 & 5 & 5 & 5 \\
\hline Minimum & 1 & 1 & 1 & 1 & 1 & 3 \\
\hline Maximum & 5 & 5 & 5 & 5 & 5 & 5 \\
\hline
\end{tabular}

Source: Survey result, 2018 (LACC $=$ Lack of access to finance, FWOC $=$ Shortage of working capital, HCOLLAT $=$ high collateral requirement, FLODELI = Complexity Loan delivery procedure, SFOXC $=$ Shortage of foreign currency, INSEXR= Instability of exchange rate)

\subsubsection{Institutional Factors}

As indicated in table 4.2 below, the majority 55(96.4\%) faced a severe problem of government support and coordination while $2(3.6 \%)$ of the respondents disagreed that the problem was not severe. The descriptive statistics result is asymmetric which is the mean value is equal to 4 . This supports the fact that weak government support and coordination significantly affect the manufacturing firms. On the other hand, the majority $46(80.7 \%)$ strongly believed that business regulation has an impact on manufacturing firms and the remaining 11(19.3\%) disagreed on the problems. The median value is 4 which imply that it has a significant impact on firms. 41(72\%) of respondents express that tax regulation and legal system was a significant impact on manufacturing firms, however, $14(24.6 \%)$ of them disagreed and 2(3,5\%) undecided on the problem. The median value (4) strengthens this statement and shows that manufacturing firms were affected by this problem. Flexible tax regulation and legal system are very critical for encouraging manufacturers. Regarding the absence of investment promotion agency $50(87.7 \%)$ of respondents agreed that the factors influencing the firms, however, $7(12.3 \%)$ differ their ideas. The middle value is 4 shows that the absence of investment promotion has an impact on manufacturing industries. It was also believed that $50(87.7 \%)$ of those manufacturing firms approved that transparency of government rules and regulation are a basic problem for manufacturing industries, but $7(12.3 \%)$ disagreed on the problem. Descriptive statistics summarized the median value (4); there are $40 \%$ of manufacturing firms affected by government rules and regulation. This is evident that $35(52.6 \%)$ of respondents were strongly proven that there was policy uncertainty while $21(36.9 \%)$ revealed that does not have an adverse impact on manufacturing firms even though $1(1.8 \%)$ undecided. The study found that the median is four. This indicates that policy uncertainty has an impact on firms. Similarly, this is followed by 54(94.7\%) of the respondents either agreed or strongly agreed that the extent of business supporting service was poor and hampering manufacturing industries, but $3(5.3 \%)$ were disagreed. The midpoint is 4 . The majority 53(93\%) of the respondents also powerfully confirmed that there was a basic problem of land delivery procedure though $4(7 \%)$ of them disagreed on the issues. The absolute middle value of scores for land delivery is 5. This indicates that land delivery procedure was complex for manufacturing firms. The table below demonstrates that the majority $50(87.7 \%)$ of the respondents were indicated the existence of poor management of existing industrial village even though $7(12.3 \%)$ disagreed. The median is 4 which have a positive opinion on this problem. The majority $50(87.7 \%)$ also confirmed that there was a problem of providing quality investment profile for manufacturing industries, thus it has some clarities on the clearly identifying the availability of resources, $5(8.8 \%)$ were disagreed, however, $2(3.5 \%)$ were refrained themselves from answering this question. The median value (4) indicates that to the option "strongly agreed or agreed and supports the above claim. Finally, 33(57.9\%) of the manufacturing firms also indicated that the foreign exchange regulation was a problem of a large number of manufacturers being effectively functioning their activities even though $23(40.4 \%)$ disagreed and $1(1.8 \%)$ of them undecided. The midpoint is 4 ; this implies that the majority of respondents prove that institutional factors have a strong impact on manufacturing industries. 
Table 4.2: Percentage of Institutional Factors

\begin{tabular}{|c|c|c|c|c|c|c|c|c|c|c|c|}
\hline Responses & PGSC & BUSR & TAXRLS & ABIPA & TGRR & POLIUN & BSS & CLDP & LIIEN & QIP & FOXR \\
\hline $\begin{array}{c}\text { Strongly } \\
\text { agree }\end{array}$ & $24(42 \%)$ & $17(29.8 \%)$ & $14(24.6 \%)$ & $14(24.6 \%)$ & $19(33.3 \%)$ & $10(8.7 \%)$ & $21(36.8 \%)$ & $33(57.9 \%)$ & $19(33.3 \%)$ & $18(31.6 \%)$ & $13(22.8 \%)$ \\
\hline Agree & $31(54.4 \%)$ & $29(50.9 \%)$ & $27(47.4 \%)$ & $36(63.1 \%)$ & $31(54.4 \%)$ & $25(43.9 \%)$ & $33(57.9 \%)$ & $20(35.1 \%)$ & $31(54.4 \%)$ & $32(56.1 \%)$ & $20(35.1 \%)$ \\
\hline Disagree & $1(1.8 \%)$ & $10(17.5 \%)$ & $14(24.6 \%)$ & $6(10.5 \%)$ & $6(10.5 \%)$ & $18(31.6 \%)$ & $2(3.5 \%)$ & $4(7 \%)$ & $5(8.8 \%)$ & $4(7 \%)$ & $20(35.1 \%)$ \\
\hline $\begin{array}{c}\text { Strongly } \\
\text { disagree }\end{array}$ & $1(1.8 \%)$ & $1(1.8 \%)$ & - & - & $1(1.8 \%)$ & $3(5.3 \%)$ & $1(1.8 \%)$ & - & $2(3.5 \%)$ & $1(1.8 \%)$ & $3(5.3 \%)$ \\
\hline Undecided & - & - & $2(3.5 \%)$ & $1(1.8 \%)$ & - & $1(1.8 \%)$ & - & - & - & $2(3.5 \%)$ & $1(1.8 \%)$ \\
\hline Median & 4 & 4 & 4 & 4 & 4 & 4 & 4 & 5 & 4 & 4 & 4 \\
\hline $\begin{array}{c}\text { Upper } \\
\text { Quartiles }\end{array}$ & 5 & 5 & 4 & 4.5 & 5 & 4 & 5 & 5 & 5 & 5 & 4 \\
\hline Minimum & 2 & 2 & 1 & 1 & 1 & 1 & 2 & 3 & 1 & 1 & 1 \\
\hline Maximum & 5 & 5 & 5 & 5 & 5 & 5 & 5 & 5 & 5 & 5 & 5 \\
\hline
\end{tabular}

Source: Survey result, 2018: $\mathrm{PGSC}=$ poor government support and coordination, BUSR = Business regulation, $\mathrm{TAXRLS}=$ tax regulation and legal system, $\mathrm{ABIPA}=$ Absence of investment promotion agency, $\mathrm{TGRR}=$ Transparency of government rules and regulations, POLIUN= Policy uncertainty, BSS $=$ Business supporting service, $\mathrm{CLDP}=$ Complexity of land delivery procedure, $\mathrm{POLCI}=$ policy coherence and inclusiveness, $\mathrm{QIP}=$ Quality of investment profile, FOXR= Foreign currency regulation

\subsubsection{Infrastructure Factors}

As shown in table 4.3 below, the majority $57(100 \%)$ of respondents was strongly believed that at present electric power supply had a direct impact on the productivity of manufacturing firms. The median value is 5 . The implication of this is that electrical power/ power interruption severely hinder manufacturing firms. It was also believed that $43(75.4 \%)$ of those who were agreed that the shortage of water supply are a serious problem for manufacturing industries. However, $12(21.1 \%)$ of respondents strongly disagreed and only $2(3.5 \%)$ disagreed on the problem. The median value is (4) which indicate that water supply is a severe problem for industries. Similarly, this is followed by $50(87.7 \%)$ of the respondents which means that the extent of the sewerage system was poor and influencing on the manufacturing firms, but $7(12.3 \%)$ were disagreed. The median value for this claim is 4, which the majority of firms have a positive opinion that there is the existence of poor sewerage system. Regarding access to land $49(85.9 \%)$ of respondents were agreed on the problem of access to land though $7(14.1 \%)$ disagreed. The middle value is 4 that implies that the central value of firm owners agree that there was a difficulty of getting land for investment. This is evident that $44(77.2 \%)$ of respondents were strongly proven that there is not enough road access in the manufacturing industry site, thus it is a severe problem facing manufacturing firms. Whereas $13(22.8 \%)$ of respondents revealed that does not have an impact on firms. The middle value for this involvedness is 4 that assure there is no road access for firms. To sum up, the implication of these findings was that shortage of electric power supply, poor sewerage system, lack of access to land, shortage of water supply, and lack of access to the road were major factors influencing the manufacturing firms, which has a significant impact on the survival, growth, and performance of manufacturing industries. Because the number of responses to the options "agree" and "strongly agree" is about five times greater than the responses to the option "disagree" and "strongly disagree". This adds to the fact that infrastructural factors drastically affect manufacturing firms. Thus, it seeks special attention from government to overcome these constraints by creating strong support and coordination with other related governmental offices. The interview result from TIIB and DIO agreed that power interruption, sewerage system and road construction inside an industrial village are the problems that firms exposed to properly functioning their operations. The respondents, however, pointed out that the main roads are under construction, but the rest side of Hamdil village still no road inside the village. The result supports the finding from the interview.

Table 4.3: Percentage of Infrastructure Factors

\begin{tabular}{|l|r|r|r|r|r|}
\hline Responses & SPS & SWS & PSS & LAL & LARO \\
\hline Strongly agree & $45(79 \%)$ & $21(36.8 \%)$ & $24(42.1 \%)$ & $24(42 \%)$ & $15(26.3 \%)$ \\
\hline Agree & $12(21 \%)$ & $22(38.6 \%)$ & $26(45.6 \%)$ & $25(43.9 \%)$ & $29(50.9 \%)$ \\
\hline Disagree & - & $12(21.1 \%)$ & $5(8.8 \%)$ & $5(8.8 \%)$ & $7(12.3 \%)$ \\
\hline Strongly disagree & - & $2(3.5 \%)$ & $2(3.5 \%)$ & $2(5.3 \%)$ & $6(10.5 \%)$ \\
\hline Undecided & - & - & - & - & - \\
\hline Median & 5 & 4 & 4 & 5 & 5 \\
\hline Upper Quartile & 5 & 5 & 2 & 2 & 5 \\
\hline Minimum & 4 & 2 & 5 & 5 & 2 \\
\hline Maximum & 5 & 5 & 5 & 5 \\
\hline
\end{tabular}

Source: Survey result, 2018 (SPS= Shortage of electric power supply, SWS= Shortage of water supply, PSS= Poor sewerage system, $\mathrm{LAL}=\mathrm{Lack}$ of access to land, $\mathrm{LARO}=$ Lack of access to the road) 


\subsubsection{Social Factors}

As one can see from the below table 4.4, 42 (73.6\%) of respondents strongly believe that lack of access to skills has an impact on the manufacturing firms though 14(24.6\%) hold different views and only 1(1.8\%) unconvinced. The central point is 4 indicating that most respondents reported there was a limitation of access to skilled manpower. Regarding marketing knowledge $38(66.7 \%)$ of respondents approved that there is a strong marketing knowledge problem that affects manufacturing firms, but 17 (29.9\%) moved away from the expected responses and $2(3.5 \%)$ of respondents were still in doubt on this problem. The median value is (4) a large number of manufacturers there was a high level of constraints exist between firms. 53 (93\%) of respondents stated that there is community lifestyle that has an impact on growth and survival of manufacturing firms while $4(7.1 \%)$ revealed that does not have an effect on the firms. The middle value is 4 , which reflects that a majority of firms reported that their firms affected by this problem. Similarly, this is followed by the absence of effective demand $38(66.6 \%)$ of respondents asserted that there is a problem of getting effective demand, but $18(31.6 \%)$ stated that there was no impeding the manufacturing firms and 1(1.8\%) not given their opinions. The midpoint is 4 , which indicating there was a problem. This is followed by linkage with value chains with $37(64.9 \%)$ of those who were convinced that there is a problem of linkage with value chains though about $19(33.4 \%)$ disagreed and 1(1.8) reserved from providing their responses on the problem. The middle value for value chain is 4 .

It was also believe that $45(78.9 \%)$ of those who strongly believe that expansion of illegal trade has a negative impact on the manufacturing firms survival, growth and performance in the study area though 11(19.3\%) of respondents differ their ideas and indicated that no significance variation on their product, but only $1(1.8 \%)$ of them uncertain and resolved from giving the opinion. The midpoint score of illegal trade is 4 . Finally, $48(84.2 \%)$ of respondents revealed that the working culture of the community in the study area is not good and poor as a result it has a significant impact in the manufacturing firms, but $9(15.9 \%)$ disagreed that the existing working culture does not have an effect on the firms. The central point of this variable is 4 . This implies that the majority of respondents strongly confirms and approve that social factors have a significant impact on manufacturing industries.

The interviews with firm owners and governmental officials revealed the existence of various types of social factors pressures the manufacturing firms. The buying habits and the attitude of society towards domestic product are weak, they focus on foreign goods than domestic products as a result firm forced to sell their final product to the countryside and other regions. They stated that society lacks understanding of the firms' product, as a result, they prefer to buy imported products. Furthermore, poor saving, investing, working culture of the society, time utilization habits, and addiction to various things affect the survival, growth, and performance of manufacturing firms. The responses of manufacturing firm owners were similar to that of the above interviewee in which most of them explained that social factors affect the manufacturing firms' performance. The following table 4.4 depicts that percentage of social factors.

Table 4.4: Social Factors

\begin{tabular}{|l|r|r|r|r|r|r|r|}
\hline Responses & LAS & LMK & CLS & LAED & W LIVC & EILT & WC \\
\hline Strongly agree & $12(21 \%)$ & $16(28.1 \%)$ & $7(12.3 \%)$ & $5(8.8 \%)$ & $10(17.5 \%)$ & $26(45.6 \%)$ & $14(24.6 \%)$ \\
\hline Agree & $30(52.6 \%)$ & $22(38.6 \%)$ & $46(80.7 \%)$ & $33(57.8 \%)$ & $27(47.4 \%)$ & $19(33.3 \%)$ & $34(59.6 \%)$ \\
\hline Disagree & $9(15.8 \%)$ & $14(24.6 \%)$ & $3(5.3 \%)$ & $13(22.8 \%)$ & $16(28.1 \%)$ & $8(14 \%)$ & $8(14 \%)$ \\
\hline Strongly disagree & $5(8.8 \%)$ & $3(5.3 \%)$ & $1(1.8 \%)$ & $5(8.8 \%)$ & $3(5.3 \%)$ & $3(5.3 \%$ & $1(1.8 \%)$ \\
\hline Undecided & $1(1.8 \%)$ & $2(3.5 \%)$ & - & $1(1.8 \%)$ & $1(1.8 \%)$ & $1(1.8 \%)$ & - \\
\hline Median & 4 & 4 & 4 & 4 & 4 & 4 & 4 \\
\hline Upper Quartiles & 4 & 5 & 4 & 4 & 4 & 5 & 4.5 \\
\hline Minimum & 1 & 1 & 2 & 1 & 1 & 1 & 2 \\
\hline Maximum & 5 & 5 & 5 & 5 & 5 & 5 & 5 \\
\hline
\end{tabular}

Source: Survey result, $2018(\mathrm{LAS}=$ Lack of access to skills, LMK= Lack of marketing knowledge, CLS $=$ Consumer lifestyle, $\mathrm{ED}=$ Lack of access to effective demand, WLIVC $=$ Weak linkage with value chains, ILT $=$ Expansion Illegal trade and $\mathrm{WC}=$ Working culture

\subsubsection{Economic Factors}

The table 4.5 below shows that $34(59.6 \%)$ of respondents opinions that at the present interest rate has a significant impact in the manufacturing industries while $4(7 \%)$ their opinions differ from other responses and only $1(1.8 \%)$ in doubt on the problem. The median of 5 indicates that the center of interest rate is affected by the firms. This implies that high-interest rate tends to increase the cost of borrowing, high mortgage interest payments, increase the return to savings (investors prefer to save rather than spend/invest), resulting in reduced investment, consumption and low economic growth. This will lead to a decrease in aggregate demand. This is also followed by inflation rate with $51(89.5 \%)$, which means that the extent of inflation rate significantly affect the growth and performance of manufacturing firms in the study area even though $5(8.8 \%)$ of firm owners 
deviate from their responses but only $1(1.8 \%)$ detached from giving their feelings. The middle value of the inflation rate is 5 , which demonstrate there was an impact on firms. Thus, the number of responses to the option "strongly disagree, disagree and undecided" is less than the number of responses to the option "strongly agree" and "agree" indicating that economic factors significantly affect the manufacturing industries. Generally, this implies that high interest and inflation rate tend to decrease the rate of private investment inflows in the area, but normal inflation and interest rate do not have a negative impact on private investment in the manufacturing sector. In addition, the findings imply that the cost of access to credit facilities increases, the growth of manufacturing firms constrained, which results in a decline the manufacturing firm operational performance. The high inflation rate also has a negative impact on the cost of acquiring capital thus less significant for capital formation, hence adversely affect private investment in manufacturing firms.

The interviews with firm owners also confirmed that various economic factors affect the survival, growth, and performance of manufacturing firms, such as high-interest rate, inflation rate, instability of exchange rate, shortage of foreign currency, paying ability of customers and low-income level of the community. The effect of these will tend to reduce investment inflows in the study area, weak market competition, high unemployment, inadequate infrastructure, and investors prefer to save their money rather than spending. These resulted in a negative impact on finance accessibility, productivity, capacity utilization, weak improvement of firms' efficiency and quantity of the product which in turn has an impact on government revenue, RGDP contribution, resulting in poor infrastructure and service provision. Respondents also pointed out that it was too difficult for them to meet the needs of their desire goal because of the high-interest rate demanded by the banks. This tends to reduce private investors from borrowing confidences. As a result, investors prefer to save their money rather than investing and unwillingness to take high risks. The consequence of this is that there is no investment will tend to reduce the number of unemployed people, and low economic growth.

The interview with governmental and non-government officials from commercial banks and private banks revealed that when the interest rate become high, the number of borrowers of private investors will be less, thus they do not want to take high risks rather they want to save their money. When we observe the interest rate data reported that for the last five years was high as compared to other years. This suggests that the high-interest rate and inflation rate poses serious problems for manufacturers. Clearly, this will slow down productivity and growth of manufacturing firms unless the government is improved, and reduced. These findings from the survey were validating from interview and observation.

Table 4.5: Percentage of Economic Factors

\begin{tabular}{|l|r|r|}
\hline Responses & HIntR & HInfR \\
\hline Strongly agree & $34(59.6 \%)$ & $33(57.9 \%)$ \\
\hline Agree & $18(31.6 \%)$ & $18(31.6 \%)$ \\
\hline Disagree & $4(7 \%)$ & $5(8.8 \%)$ \\
\hline Strongly disagree & - & - \\
\hline Undecided & $1(1.8 \%)$ & $1(1.8 \%)$ \\
\hline Median & 5 & 5 \\
\hline Upper Quartiles & 5 & 5 \\
\hline Minimum & 1 & 1 \\
\hline Maximum & 5 & 5 \\
\hline
\end{tabular}

Source: Survey result, 2018 (HIntR= High-interest rate, HInfR= High inflation rate)

\subsubsection{Environmental Factors}

The respondents were also asked to express their level of agreement or disagreement with some statements relevant to environmental factors in their respective of manufacturing industries. Accordingly, the majority 33 $(57.9 \%)$ of respondents indicate that either agreed or strongly agreed that unplanned industrial growth has a significant impact on the environment, but 24(42.1\%) reveal that does not have a negative effect on the environment. The median of this factor is 4 that means half of the firms extremely affect the environment and half of them less influenced by the problem. 28 (49.1\%) of respondents strongly supposed hat hazardous waste disposal definitely has an impact on the environment though $29(50.9 \%)$ disproved that factors do not have an impact on the environment.

The median value of (3) reflecting that half of the respondents well confirm that the problem affects the manufacturing firms while the other firms less confirmed. This is also evident that $27(47.3 \%)$ of respondents either agreed or strongly agreed that disposing outdated machinery and equipment has a negative impact on the environment, though about $29(50.9 \%)$ of the majority of respondents disagreed and only $1(1.8 \%)$ unable to give the opinion on the provided problems. The central point of this factor is $3.21(36.9 \%)$ of respondents agreed that releasing toxic gases from manufacturing industries has a significant effect on the environment, but 34(59.6\%) of them disagreed on this factor and 2(3.5\%) reserved from giving their argument. The mean value of (3.28) is higher than the median (3) which have an effect on the environment. The median result indicates that most of the 
environment affected by industrial influents.

Similarly, $30(52.6 \%)$ of those who believed that use of outdated technologies has an effect on the environment though about $25(43.8 \%)$ disagreed and 2(3.5\%) undecided on the problem. The mean of (3.42) is less than the median (4) indicating that less impact on the environment, but the midpoint reveal that the average of the environment affected by industries. The implication of this is that using outdated technologies reduce the efficiency and productivity of manufacturing firms, resulting in wasting precious time. However, modern technologies can support enabled business environment to be competent in the global and domestic markets. It was evident from the table that $34(59.6 \%)$ of respondents were given the opinion of ineffective industrial land use planning for manufacturing firms adversely affect the environment though $15(26.3 \%)$ and $6(10.5 \%)$ were stated that the mentioned factors do not affect the manufacturing industries. The median of (4) implies that ineffective industrial land use planning exposes for environmental pollution by discharging liquid, toxic gases, noise, water, and solid waste unless properly planned industrial land. Regarding greenhouse gas emission 22 (38.6\%) of respondents noted that the extent of greenhouse gas emission has a significant effect on the environment, though $33(57.9 \%)$ disagreed and $2(3.5 \%)$ unable to decide on the problem. The middle values of 3 , which indicate that on average of greenhouse gas emission, have an impact on the environment. 44 (77.1\%) of respondents agreed that there is a lack of awareness about environmental protection, though $12(21.1 \%)$ indicate that awareness does not have relation and impact on the environment, but $1(1.8 \%)$ undecided to give the responses. The median of (4) stated that there is a significant effect. The implication of this is that $77.1 \%$ of respondents do not have awareness of the rules and regulation on how to protect the environment. The majority $36(63.2 \%)$ of manufacturing firms depict that there was a problem of checking noise emanated from the factory while $20(35.1 \%)$ their response differ that does not have an effect on the environment and only $1(1.8 \%)$ disinterested to give the opinion. The central value of this factor is (4) shows that those firms highly proved that it has an effect and the other reported that never effect on the environment. The table below demonstrates that the majority ( 42 or $73.6 \%$ ) of the respondents stated that there was lack of adopting implementing effective strategies to mitigate the environmental problems, however, $14(24.5 \%)$ of them having different ideas and $1(1.8 \%)$ was reserved. The mean of (3.77) less than the median (4), which entails that most of the firms influencing the environment due to the lack of effectively implementing the policies and strategies. This finding suggests that various types of environmental factors affecting the environment which was emanated from manufacturing industries. Accordingly, it requires the government to adopt and implement new strategies to protect the environment and also need to create awareness to various community members, and manufacturers in terms of preparing seminar, practical training to reduce the waste emanated from firms. Respondents were asked about environmental factors. The respondents pointed out several environmental factors affecting the manufacturing firms due to the ignorance of irresponsible business owners to minimize various environmental impacts, unplanned industrial growth, lack of ways to reduce high energy consumption and substituting renewable energy; deforestation, releasing poison gases, lack of policies to control pollution and waste disposal, poor land management and infrastructure fulfillment. All of these problems tend to exacerbate global warming. They also agreed that various techniques require holding and minimizing the environmental factors through making an intensive supervision, planting more trees around the buffer area for environment protection, strictly implementing environmental policies and strategies, rules and regulation, creating awareness to build the image of the manufacturing firms, civil society and stakeholders, consistent auditing and inspecting the manufacturing firms. In the case of Dire Dawa, the interviewees indicated that manufacturing firms adversely affect on the environment in terms of improper disposing waste materials, chemicals and substance, toxic gases, greenhouse gas emission into the air and nearby stream which pollutes water, air, human and animal life, and destructs many natural resources. The consequence brings severe problems in terms of soil degradation, various diseases in human life; decrease the fertility of plants, and climate change, such as global warming. This result suggests that manufacturing industries have an effect on the environment, therefore, it requires categorizing different industrial sites by considering the environmental issues and need to initiate manufacturing firms to use go green environment-friendly. Furthermore, DDEPA needs to limit the pollution of firms to release into water, air and obliged selecting environmentally friendly investment with the collaboration of investment office and land management and development bureau. Table 4.6 depicts the percentage of environmental factors. 
Table 4.6: Environmental Factors

\begin{tabular}{|c|c|c|c|c|c|c|c|c|c|c|}
\hline Responses & UIG & HWD & OMED & RTG & UODT & IUP & GHGE & LOAW & NEFA & AIES \\
\hline Strongly agree & $7(12.3 \%)$ & $15(26.3 \%)$ & $8(14 \%)$ & $9(15.8 \%)$ & $4(7 \%)$ & $6(10.5 \%)$ & $3(5.3 \%)$ & $13(22.8 \%)$ & $11(19.3 \%)$ & $10(17.5 \%)$ \\
\hline Agree & $26(45.6 \%)$ & $13(22.8 \%)$ & $19(33.3 \%)$ & $12(21.1 \%)$ & $26(45.6 \%)$ & $28(49.1 \%)$ & $19(33.3 \%)$ & $31(54.3 \%)$ & $25(43.9 \%)$ & $32(56.1 \%)$ \\
\hline Disagree & $21(36.8 \%)$ & $20(35.1 \%)$ & $23(40.4 \%)$ & $24(42.1 \%)$ & $19(33.3 \%)$ & $15(26.3 \%)$ & $24(42.1 \%)$ & $9(15.8 \%)$ & $16(28.1 \%)$ & $8(14 \%)$ \\
\hline Strongly disagree & $3(5.3 \%)$ & $9(15.8 \%)$ & $6(10.5 \%)$ & $10(17.5 \%)$ & $6(10.5 \%)$ & $6(10.5 \%)$ & $9(15.8 \%)$ & $3(5.3 \%)$ & $4(7 \%)$ & $6(10.5 \%)$ \\
\hline Undecided & - & - & $1(1.8 \%)$ & $2(3.5 \%)$ & $2(3.5 \%)$ & $2(3.5 \%)$ & $2(3.5 \%)$ & $1(1.8 \%)$ & $1(1.8 \%)$ & $1(1.8 \%)$ \\
\hline Median & 4 & 3 & 3 & 3 & 4 & 4 & 4 & 4 & 4 & 4 \\
\hline Upper Quartiles & 4 & 5 & 5 & 4 & 4 & 4 & 4 & 4 & 4 & 4 \\
\hline Minimum & 2 & 2 & 1 & 1 & 1 & 1 & 1 & 1 & 1 & 1 \\
\hline Maximum & 5 & 5 & 5 & 5 & 5 & 5 & 5 & 5 & 5 & 5 \\
\hline
\end{tabular}

Source: Survey result, 2018 (UIG= Unplanned Industrial growth, HWD=Hazardous waste disposal, $\mathrm{OMED}=$ Outdated machinery, and equipment disposal, $\mathrm{RTG}=$ Releasing toxic gases, UODT=Use of outdated technologies, ILUP=Ineffective industrial land use planning, GHGE= Greenhouse gas emission, LOA=Lack of awareness, NEFA= Noise emanated from factories, AIES= Adopting and implementing effective strategies)

\subsubsection{Political Factors}

Table 4.7 below depicts that $55(96.5 \%)$ of respondents agreed that bureaucratic red tape definitely affects the manufacturing firms but, 2(3.6\%) unbiased to give their responses. The median of (4) implies that most of firms operations powerfully influenced by bureaucracy and some of them weakly affected. $15(26.3 \%)$ of manufacturing firms agreed that tax policy affects the manufacturing firms', though a majority (42 or $73.6 \%)$ of firms disagreed on the problem of having tax policy affecting the firms. The middle value for tax policy is 4 , which specify that factor adversely affect the firms. $30(52.6 \%)$ of those who strongly believe that import restriction has an impact in the manufacturing industries while $27(47.4 \%)$ stated that there were not impact on the manufacturing firms. The central value of (4) shows that a large number of firms affected by these problems. Similarly, $35(61.4 \%)$ of respondents were stated that the extent of trade control has a significant impact on the manufacturing industries, though about $22(38.6 \%)$ disagreed on the problem. The middle value of trade control is 4 indicating that most firms affected by trade control while there is a few of them not influenced by the factor. This is also followed by $37(64.9 \%)$ of respondents disagreed that employment laws do not have a negative impact while $20(35.1 \%)$ agreed on the problem. The median of 3 implies that most firms confirmed that opposed that does not have an impact on firms, but only a few firms agreed. This result implies that import restriction, trade control, bureaucracy, employment laws, and tax policy are the major political factors in the investment climate constraints that hindering the manufacturing industries. The respondents were also asked to indicate whether the political factors affecting the manufacturing firms. The respondents argue that political influences the manufacturing firms' by disturbing the firms' regular operation and create inconsistency in the marketing strategic process. They also revealed that other factors need to take into account that distress the factories like bureaucratic red tape, changing government rules and regulation. The other basic problem is political instability, taxes and government spending for public investment, and security, which significantly affect on sales, productivity, and decision making of firms, instability of government revenue from taxes, business operation and the economy. These were the main political factors making not conducive to firm investors.

The interviews with the firm owners and government officials also revealed that due to changing rules and regulation of government institutions, political instability, bureaucracy, corruption, trade control, and employment laws affect the firm's business environment. Thus, changing the political factors can affect the manufacturing local market, customers, suppliers, and the overall economic environment.

During the observations of manufacturing firms' site, it was found that political instability was the basic hurdles. Some manufacturing industries were closed for three days until stabilized the area. This result indicates that the problem of political instability was very severe in study sites. Thus, this demands immediate intervention from concerned bodies to improve and stabilize the political system. The findings of this study emphasize the fact that the proportion of manufacturing firms that had ever was small. This is the result of the limited political system have in the area, as a result, firm owners fear risks to investing their capital. In addition, the findings also indicate that government institutions have more problems in stabilizing and harmonizing the political system. This study can be concluded that conducting business activities mainly in the study area may be difficult due to various political uncertainties. Thus, it seeks to build a strong relationship between government institutions by clearing up the enormous bureaucracy and stabilizing the political system. The table below 4.7 asserts that political factors. 
Table 4.7: Political Factors

\begin{tabular}{|c|c|c|c|c|c|}
\hline Responses & $\mathrm{BU}$ & $\mathrm{TP}$ & IR & $\mathrm{TC}$ & EL \\
\hline Strongly agree & $25(43.9 \%)$ & $2(3.5 \%)$ & $3(5.3 \%)$ & $8(14 \%)$ & $4(7 \%)$ \\
\hline Agree & $30(52.6 \%)$ & $13(22.8 \%)$ & $27(47.3 \%)$ & $27(47.4 \%)$ & $16(28.1 \%)$ \\
\hline Disagree & $1(1.8 \%)$ & $34(59.6 \%)$ & $22(38.6 \%)$ & $19(33.3 \%)$ & $28(49.1 \%)$ \\
\hline Strongly disagree & $1(1.8 \%)$ & $8(14 \%)$ & $5(8.8 \%)$ & $3(5.3 \%)$ & $9(15.8 \%)$ \\
\hline Undecided & - & - & - & - & - \\
\hline Median & 4 & 3 & 4 & 4 & 3 \\
\hline Upper quartiles & 5 & 4 & 4 & 4 & 4 \\
\hline Minimum & 2 & 2 & 2 & 2 & 2 \\
\hline Maximum & 5 & 5 & 5 & 5 & 5 \\
\hline
\end{tabular}

Source: Survey result, $2018(\mathrm{BU}=$ Bureaucracy, $\mathrm{TP}=$ Tax policy, $\mathrm{IR}=$ Import restriction, $\mathrm{TC}=$ Trade control, $\mathrm{CR}=$ competition regulation, $\mathrm{EL}=$ Employment laws)

\subsubsection{Raw Material Availability}

Figure below demonstrates that 27 (47\%) of the sampled factories uses both domestic and foreign raw materials, $21(37 \%)$ of the firms' are dependent on domestic raw materials such as agro-processing, textile, purified mineral water, plastic factory, woodwork, construction material manufacturing, $9(16 \%)$ are depending on foreign (imported raw materials: chemical and chemical product, metal and steel factories, electronics and others. The most often value is 3 that the majority of firms uses both domestic and foreign raw materials and the range is 2. The result implies that most of manufacturing sector, such as agro-processing (wheat flour and coffee processing) production process of producing depending on domestic raw materials as a result the quality of raw materials affected by the fluctuation of weather conditions (seasonality) and inconsistency of raw materials supply is one of the major bottleneck of manufacturing firms to produce and cover the large demand of their product. Figure 4.8 below shows regarding raw material availability of the manufacturing firms.

Figure 4.8: Raw Material Availability

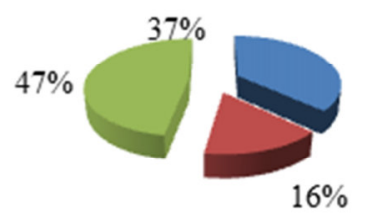

Domestic market

Foreign market

Both Domestic and Foreign Market

Source: Survey result, 2018

\subsubsection{Reason for Depending on Imported Raw Materials}

As shown table 4.8, the major reason for depending on imported raw materials $11(19.3 \%)$ of respondents replied that the shortage of raw materials in the local market, $7(12.3 \%)$ insufficient raw material suppliers, $8(14 \%)$ quality problem, $7(12.3 \%)$ no one produce/supply, $2(3.5 \%)$ no raw material suppliers and $2(3.5 \%)$ all. However, $20(35.1 \%)$ of firms are independent of imported raw materials. The most frequent value of 1, which shows the largest number of firms depend on imported raw materials. The result shows that manufacturing industries depend on imported raw materials as a result of various reasons. It is clear that these sectors need a strong market and industrial linkage with agriculture, inter-firm and intra-firm, resulting in technology transferring, and capacity utilization. Besides, it needs government and other stakeholders support through creating supply chain linkage and reducing the foreign currency shortage.

Table 4.8: Reason for Depending on Imported Raw Materials

\begin{tabular}{|c|c|c|}
\hline Reasons & Frequency & Percent \\
\hline Shortage of raw materials & 11 & $19.3 \%$ \\
\hline Insufficient raw material suppliers & 7 & $12.3 \%$ \\
\hline Quality problem & 8 & $14 \%$ \\
\hline No one produce/supply & 7 & $12.3 \%$ \\
\hline No raw material suppliers & 2 & $3.5 \%$ \\
\hline All others & 2 & $3.5 \%$ \\
\hline Total & 37 & $64.9 \%$ \\
\hline
\end{tabular}

Source: Survey result, 2018

\subsubsection{Economic Capacity Utilization Rate}

Capacity utilization plays a significant role in the manufacturing industries. It has associated with firms' productivity, employment, capital, market demand, and output. The figure below indicate that $23(40.4 \%)$ of sampled firms the production capacity was ranged from 51-75\%, $21(36.8 \%)$ from $26-50 \%, 7(12.3 \%)$ from 76 - 
$100 \%$, but only $6(10.5 \%)$ respondents rating its production capacity underutilization from $10-25 \%$. The median of firms' capacity utilization rate is (4), which indicate most of the manufacturing firms are characterized by capacity underutilization which reflects on efficiency and quality of manufacturing firms' product. It is clear that the government need to improve job creation by a rising number of a hopeful young industrialist who has the potential skill to be competent in the large market. The main justification behind this is that the firm owner should come up with new innovative ideas to use the most obtainable capacities. Furthermore, manufacturing firms need to promote and introduce their product following new ways by assessing which product value can be increased in order to maximize the production capacity utilization rate. In general, the study can be summarized that the manufacturing firms should prepare proper planning, strategic approach and decision to improve firms' capacity utilization. Figure 4.9 below shows regarding capacity utilization of the manufacturing firms.

Figure 4.9: Capacity Utilization Rate

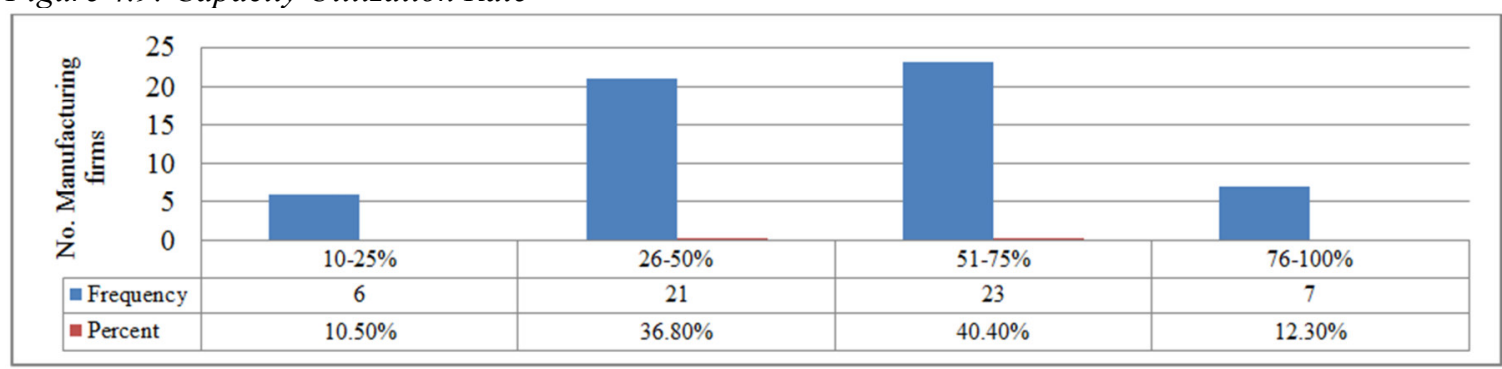

Source: Survey result, 2018

\subsubsection{Reason for Capacity Underutilization}

Respondents were asked the questions regarding the main reason for capacity underutilization. The findings of the survey result figure 4.10 revealed that $26(18.7 \%)$ of respondents replied that raw material shortages, $6(4.3 \%)$ lack of effective demand, 9 (6.5\%) lack of well-trained manpower, 19 (13.7\%) infrastructure problem, $15(10.8 \%)$ working capital shortage, $4(2.9 \%)$ machine breakdown and poor maintenance, $4(2.9 \%)$ high competition, $6(4.3 \%)$ weak managerial capacity, $1(0.7 \%)$ shortage of intermediary inputs, $15(10.8 \%)$ shortage of foreign exchange, $3(2.2 \%)$ high inflation, $7(5 \%)$ high interest rate $1(0.7 \%)$ high transportation costs and $22(15.8 \%)$ no reason. This finding suggests that capacity underutilization that reflects the firm's final output. Respondents in this study were asked about the improvement of the firm's production capacity. Their responses are improving firm production capacity is very crucial through adopting modern technology, increasing labour productivity, creating a conducive environment for employees, enhancing market competition, promoting research and development, increasing working people, creating industrial linkages, continuous training manpower, and good payment for labour in general. This is a fact the manufacturing firms' needs special support and attention from the government to improve production capacity.

The interview with manufacturing firm owners revealed that manufacturing firms unable to operates its full capacity due to several reasons that disrupted their day-to-day production. The power interruption hamstrung manufacturing firms, preventing them from producing their product by taking the resent and additional work. They also revealed that inadequate raw materials, skilled manpower, high transportation costs and the absence of market share, .i.e. less market share, firms unattainable to utilize its maximum capacity utilization rate. In the same way, the manufacturing firms have explained that low demand for their product and shortage of foreign exchange as main problems. According to an interview with firm owners, a firm could be done over time by employing temporal persons and improving machine and equipment in order to attain a 100\% capacity utilization rate. This suggests that an industrialist encountered more operational impediment to use its full capacity. Because of these hardships, their capacity utilization seems a far-away from reality, unless making an effective interfered by government bodies. These findings imply that it needs concerned offices to take into account how the manufacturing firms improve their capacity. Therefore, it seeks to improve its production capacity using several methods and techniques. These findings from the survey were similar to those from interviews. 


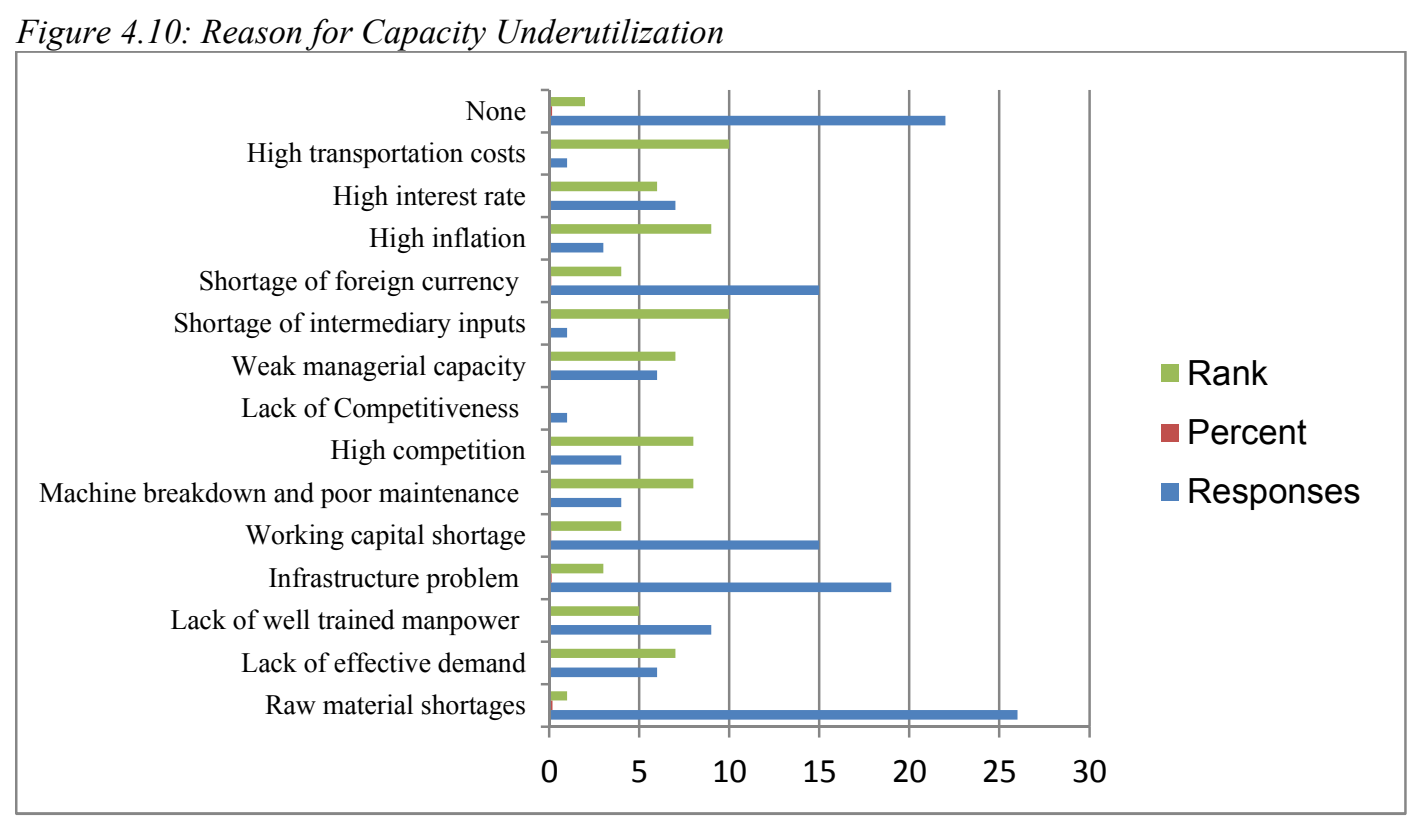

Source: Survey result, 2018

\subsection{Research Question two: The Impact of Investment Climate Constraints on Manufacturing Firms' Performance}

The researcher assessed the dependent variable of private investment in the manufacturing industry using three indicators: Productivity, quality of the product, and on time delivery. As shown in table 4.9 demonstrate that the majority $34(60 \%)$ of manufacturing firms accepted that various investment climate constraints have a significant impact on firms productivity while $21(37 \%)$ of respondents resist on the problem and the remaining $2(3 \%)$ uncertain on the issues. The median of (4), which indicate that most of the manufacturing firms performance strongly affected by constraints. It was evident that the majority (41 or $72.2 \%$ ) of respondents were considered that their firms' quality of the product influenced by investment climate constraints whereas $15(26 \%)$ disagreed on the problems and the rest $1(1.8 \%)$ uncertain on the difficulty. The middle value is (4) which indicating that it has a significant impact on firms performance. Regarding on-time delivery of firms product the majority $69(68.4 \%)$ of the firm agreed that it has an impact on delivery while $17(29.8 \%)$ disagreed and $1(1.8 \%)$ was indecisive. The midpoint value is (4) reflecting that investment climate constraints have a large effect on firm product delivery.

Table 4.9: The Extent of Manufacturing Firms' Performance

\begin{tabular}{|l|r|r|r|}
\hline Responses & PROD & QTYP & OTD \\
\hline Strongly agree & $13(23 \%)$ & $19(33.6 \%)$ & $20(35.1 \%)$ \\
\hline Agree & $21(37 \%)$ & $22(38.6 \%)$ & $19(33.3 \%)$ \\
\hline Disagree & $17(30 \%)$ & $12(21 \%)$ & $12(21 \%)$ \\
\hline Strongly disagree & $4(7 \%)$ & $3(5 \%)$ & $5(8.8 \%)$ \\
\hline Undecided & $2(3 \%$ & $1(1.8 \%)$ & $1(1.8 \%)$ \\
\hline Median & 4 & 4 & 4 \\
\hline Quartiles & 4 & 5 & 5 \\
\hline Minimum & 1 & 1 & 1 \\
\hline Maximum & 5 & 5 & 5 \\
\hline
\end{tabular}

Source: Survey result, 2018 (PROD = Productivity; QTYP = Quality of the product; OTD = on time delivery)

\subsection{Discussions of the Findings}

The chapter presents the findings of the research already exist in chapter four. Under the discussion, the findings are judged with that of other studies. From the explanations, suggestion, and association, the conclusions and the recommendations are inferred.

\subsubsection{Investment Climate Constraints Discussions}

Investment climate was considered as a major driver and accelerator of economic growth and transformation, which in turn, significantly contribute to the national economy in terms of employment, productivity and poverty reduction. The analysis in all the nine independent variables reveals that an investment climate constraint 
strongly influences the manufacturing industries in the context. Firms that consider their good working environment encouraged to perform a more dynamic socio-economic development. As the theory of constraints (1984) argues, firms often face various internal and external constraints to realize the desired goals (such as capacity underutilization, shortage of skilled manpower, policies, government rules and regulations). These constraints are strongly influencing the firm's efficiency and effectiveness. World Bank (2014) also argue that investment climate reforms that promote private sector growth by reducing bureaucratic obstacles, costs and time constraints by improving the efficiency of legal institutions. Bah and Fang (2015) depicted that business in Africa mislay large market share of their sales as a result of poor infrastructure, corruption, crime, government rules, and regulations, resulting in low production efficiency and growth. A part from the above direct effect, it was found that financial factors directly influence on manufacturing industries. This is an interesting finding of access to finance, working capital, collateral requirement, and loan delivery procedure. Firms that can adjust themselves or take a basic measurement in light of what is going in the financial sectors need to improve financial performance. In fact, different scholars (Suhendra and Anwar, 2014; Nyangoma, 2012; Adugna et al., 2015; Fiestas and Sinha, 2011) earlier argued that financial factors affect the manufacturing firms and as well as they confirm that access to finance has a positive effect on the performance of manufacturing industries (WAMIORI, G. M., et al., 2016). As Tobin Q investment theory (1969) argument that a firm may raise its physical assets by personal savings, borrowing, selling shares or equity. This finding is consistent with previous studies that access to finance has a positive relationship and a significant impact on manufacturing industries. Thus, it needs requires creating a favorable business environment in the study area.

Building an effective institutional framework is believed to improve successfully implementing the manufacturing industries such as improving service delivery system, efficiency, transparency, developing selfconfidence, qualified staff, and quality of work. It was obtained in this study that manufacturing industries influenced by various institutional factors such as poor government support and coordination, business regulation, regulation and legal system, absence of investment promotion agency, transparency of government rules and regulations, policy uncertainty, business supporting service, complexity of land delivery procedure, policy coherence and inclusiveness, quality of investment profile, and foreign currency regulation. In addition, it was observed that this variable had a significant influence in manufacturing industries because of different policies are applied a sectoral approach (at a different place) without any coordination. This study suggests that it is critical to provide fully integrated approach services of specific issues.

Infrastructure availability is one of significant effect on the firm's efficiency and effectiveness of manufacturing industries. Because these types of services enhance private investors and the sources of firms' production capacity utilization. The result in investment climate constraints also reveals that manufacturing industries are influenced by infrastructures such as electric power supply, water supply, sewerage system, access to land, and road. This finding divulges that inadequate infrastructure provision limited firms to utilize its maximum efforts in producing and improving their product in particular than cannot significantly contribute to the regional economy and unable to achieve the desired competitive advantage. As theorists (Keynesian, 1936; and regional economic development theory) argue, there is a positive relationship between investment and infrastructure. They argue that the government should spend on infrastructure, thus it is critical enhancing the manufacturing firms (Imoisi and Ephraim, 2015; Osemeke, 2011; and Adugna et al., 2015; Lemma (2014) and Ihugba, O. A., et al., 2013) emphasize inadequate infrastructure adversely affects the manufacturing industries. UNECA (2017) also argued that infrastructure deficits are one of the most barriers to industrial success in Africa. Ideally, inadequate infrastructure influences manufacturing productivity, growth, and performance, which results in the inflow of foreign direct investment and the export sector become weak. This finding suggests that the public administration need to upgrade their capacity in order to identify and implement complex government projects. The government should encourage the private sector to invest in infrastructure if the investment climate is conducive to investment. Furthermore, it requires to work together with a public-private partnership to build and operate infrastructure projects. It is very critical to public institutions should deliver better and quality services to fulfill the interest of manufacturers. It was found in this study that manufacturing industries were significantly influenced by social factors (such as access to skills, marketing knowledge, community attitudes, consumer lifestyle, access to effective demand, linkage with value chains, expansion of Illegal trade and working culture). Thus, the findings corroborate Bayai and Nyangara, 2013; Bennett et al., 2015; Osemeke, 2011; Lemma, 2014; Wangwe, S. et al.,2014; AACCSA, 2015; and IEG, S. O., 2013) argument that there is a positive relationship between social factors and manufacturing plant, which affecting the rate of return on investments and disturbing the normal working condition of manufacturing firms. The findings are consistent with previous studies.

The findings in this study reveal that economic factors influence manufacturing plant such as interest rate and inflation rate. In this regard, the findings of this study are also consistent with those of previous studies (Gjini and Kukeli, 2012; Fiestas and Sinha, 2011; Bayai and Nyangara, 2013, and Fisher, 1930), who argue that interest rate and inflation rate affects the rate of manufacturing firm growth. This evident that macroeconomic 
instability has a significant impact on manufacturing industries. Keyne's (1936) argue that the lower interest rate can stimulate higher private investors in investing their capital, resulting in the national economies shift out of the recessions, but higher interest rate tends to have a weak investment which leads to poor productivity and economic growth rate. Hailu and Debele (2015) and Makin (1983) found that inflation uncertainty, interest rate, and real money surprises have a strong impact on the economy, resulting in a fiscal deficit. These findings suggest that most manufacturers suffer high interest and inflation rate from effectively performing their business activities, which reduces their performance. Therefore, it seeks government intervention to adjust the interest and inflation rate.

The finding of this study identified the various effects of manufacturing firms on the environment. Environmental problems in the Dire Dawa city are believed to be caused by various industrial and social activities. Most pollution emanates from manufacturing industries, as a result, different types of environmental factors and pollution pose different problems on human, animals, soil, and land. The study found that the manufacturing industries significantly influencing on the environment by releasing hazardous waste disposal, out-dated machine, and equipment disposal, releasing toxic gases, use of outdated technologies, greenhouse gas emission and noise emanated from factories. They also indicated that unplanned industrial growth, industrial land use planning, lack of awareness, and lack adopting and implementing effective strategies strongly influencing on the environment. This study implies that the city needs proper planning to build a hygienic and healthy environment and need to have an updated master plan for industrial growth and development by identifying the industrial location with its waste treatment facilities (by recycling or reuse wastes) extensively minimize and protect the environment. As Tasneem, F., et al. (2016) indicate, greenhouse gas emission, water consumption, and waste disposal adversely affect on the environment. (Moses, K. et al., 2014; UNECA, 2013, Wangwe, S. et al.,2014; and DDEPA, 2013), who argue that manufacturing firms' activities contribute a lot of toxic waste, inefficient solid waste disposal, use of outdated technologies, releasing toxic gas, greenhouse gas emission to the environment, as a result, a negative impact on air, water, noise, land, sanitation problems, and a threat to development through destructing infrastructure and livelihoods. Oguntoke, O., et al., 2018; Eckelman and Sherman, 2016; Latake, P. T., et al., 2015; Cohen and Tubb, 2018) depicted that cement factory operations and greenhouse effect have a negative impact on the environment and human health. Pierre and Wondweson (2016) stated that the main sources of environmental pollution come from agricultural activities, industrial effluents, municipal wastes, domestic wastes, fuelwood burning, and vehicle emissions. The main pollutant manufacturing industries are leather, textile, dairy, beverages and food processing, and cement factory. The industrial sector releases greenhouse gas emission. The findings in the environmental factors regarding the influence of manufacturing industries on the environment are consistent with the insight and evidence in the existing literature. This suggests that the administration need to encourage manufacturers to replace disposable items into reusable in their day to day activities. It requires promoting manufacturing industries to use renewable energy and eco-friendly chemicals to reduce the contamination of underground water. Furthermore, it requires preparing a green policy for improving the cities environment and also needs to control industrial pollution through strengthening government rules and regulations.

Political factors are severe and detrimental to economic growth. It may affect the national macroeconomic performance by creating volatility and frequent policy changes. It also directly affects the productivity of firms by increasing uncertainty in the future, which results in the allocation of a few resources. Mainly, political instability reduces the productivity of firms, less investment, technological utilization, and also impedes normal working condition manufacturing firms. Although political stability is believed to improve the economic performance, it was obtained in this study those political factors which include bureaucracy, tax policy, import restriction, trade control, and employment laws significantly influence manufacturing firms' in the context. It was observed that there was political instability, weak trade control and inflexible labour laws had an important issue in search of manufacturing industries survival, growth and performance. As neoclassical theory (1963) argument development can fail due to government intervention and regulation of the economy. Keynes (1936) argues that the government directly influence the demand for goods and services by changing tax policies and public expenditures. Newman, C. et al. (2016); IEG, S. O. (2013); Wangwe, S. et al., (2014); Hashem and Irshaidat (2014), who argue that political-legal forces have a direct impact on manufacturing firms'. The survey results were consistent with the argument of (Zeb, N., et al., 2014; Fiestas and Sinha, 2011; Ihugba, O. A., et al., 2013 and Adugna et al., 2015), who pointed out that political instability affects private investment in manufacturing firms the rate of return on investment, risk aversion, destroy physical assets, thus disturbing personal saving and investments. Thus, it requires overcoming political factors to foster sustainable economic growth and transformation.

The result in the raw material availability is shown in this study that raw material strongly influencing the manufacturing industries. Availability and quality of raw material lead to produce a large volume of production. The result demonstrates that the majority of manufacturing firms depends on imported raw material due to various reasons: raw material shortage, quality problem, and insufficient raw material suppliers. The finding 
shows that raw material availability is crucial to the economic development of the manufacturing sector and government capacity. However, these sectors strongly affected by the firms' investment decisions that cross the regional boundary to collect raw material. Just as this can be no improvement without having adequate resource potential, thus it needs the industrial linkages with agricultural sectors, inter-firm, intra-firm and sideways linkage. These findings were consistent with the theory and previous studies in the raw material availability context (Alfred Weber's theory of industrial location, 1909; Haider, 2010, Mohammed Z., 2010; CSA, 2017; AACCSA, 2014, CSA, 2015). The study can be concluded that raw material available in Dire Dawa is taken as influencing factors.

Although effective capacity utilization is supposed to improve the operational performance of manufacturing firms through carrying several benefits: improved efficiency, quality of their product, productivity, reduce cost and time and improved the delivery time. It was obtained in this study that some firms are capacity underutilization which significantly influences the firms' efficiency and quality of the product. The main reason for capacity underutilization is raw material shortages, lack of effective demand, lack of welltrained manpower, infrastructure problem, working capital shortage, machine breakdown and poor maintenance, weak managerial capacity, shortage of intermediary inputs, shortage of foreign exchange, high competition, high inflation rate, high interest rate and high transportation costs. Therefore, this sector needs special support from the government to improve efficiency by overcoming various obstacles from their sources. This finding is consistent with the evidence in the theory and existing literature (the neoclassical theory of capacity utilization, 1965; Sola et al., 2013; Uma et al., 2015; and OKUNADE et al., 2018).

Weak investment climate has a significant impact on firms productivity, quality of the product and on time delivery. These findings concurred with (Giang, M. et al., 2018; and Kinda, T. et al (2011) who suggested that several factors influencing the manufacturing firms' performance.

\subsection{Summary, Conclusion and Recommendation 5.1 Summary of Findings}

The investment climate constraints had nine variables (financial factors, institutional, infrastructure, social, economic, environmental, political, raw material availability and capacity underutilization) as major obstacles for private investment in manufacturing industry.

\subsection{Conclusions}

Investment climate has a positive effect on national as well as the regional economy. A good investment climate improves policy uncertainty; reduce barriers, a surge of new investment, encourages productivity, human development, reduce poverty and unemployment. It can play a critical role in unemployment and poverty reduction. The result indicates that investment climate constraints pose binding factors on Dire Dawa manufacturing firms. The majority of respondents robustly approved that financial, institutional, infrastructure, social, economic, environmental and political factors significantly affect the manufacturing industries. These findings include the total obstacles to firm growth. Many studies have indicated that poor investment climate has an adverse effect on firm growth and performance. This paper's result shows that a good investment climate is essential to accelerate economic growth and transformation in the study area to increase the economic activity and level of productivity. If a favorable business environment is created to, the right growth and transformation will be reached and attained. There is a need for creating a good investment climate to accelerate industrialization in the area. Hence, a weak investment climate reduces the confidence of private investors to invest their assets. The administration should create favorable environment effectively and timely delivering governmental services through establishing a dynamic organizational structure. Timely and dynamic organizational structure is essential to satisfy the needs of manufacturers.

\subsection{Recommendation}

- The study findings support the access to finance has a positive effect on manufacturing firms' performance, therefore; policies should ensure having better access to financial services and financial performance of manufacturing firms. The government should ensure that firms can have access to financial services such as savings, credit, and money transfer.

- The loan delivery procedure is slow. The government should develop best and better loan delivery system by reducing complex working process and using automation that accelerates the overall process.

- The manufacturing firms need to establish industrial banks for providing access to credit and other facilities for manufacturing industries.

- Financial institutions and policymakers should facilitate new financial instruments and networking opportunities for funding of finance to firm owners through improving loan delivery procedures

- The government should solve the problem of foreign currency shortage and the instability of the exchange rate. 
- $\quad$ Top management and trade, industry and investment bureau should create an efficient, comprehensive system, and strongly harmonize various stakeholders to support manufacturers to provide industrial assistance services.

- The top management should create manufacturing technology centers. There is a need to capacitate the manufacturing firms through establishing regional association network, regional industrial based expansion. This helps to address many of the barriers facing manufacturing industries.

- $\quad$ Top management and trade, industry and investment bureau with junction should establish a new office of investment promotion agency to attract new investors, retain the existing firms. The Dire Dawa administration needs to improve the existing business environment, thus for this responsible institutions requires to develop a clear and sound strategy for investment, manage investment promotion and building the city image. Furthermore, this can help image building, advertising product of manufacturers, preparing and attending trade fairs, and reduce barriers faced firms.

- Trade, industry and investment bureau should disseminate high-quality information, regulatory decisions, and technical information to be transparent to firms. The top management of the investment office should disclose transparently the rules and regulations early to manufacturers.

- The top management and trade, industry and investment bureau should provide policy guideline integrating critical aspects that influencing manufacturing firms. Thus, manufacturers need to have policy certainty, consistency, and integrity. Policy uncertainty reduces investor confidence and investment. Furthermore, the top management, investment commission, and trade, industry and investment bureau should create and maintain stable regulatory and policy frameworks for promoting manufacturing industry.

- The Top management and finance and economic development bureau should improve and provide a reliable and stable tax policy, which can have a positive effect on economic growth and job opportunities. There is a need to promote fair and effective mechanism to create a climate of trust between government and manufacturers.

- City government should work with various stakeholders to build a smart city. In particular, the land development and management bureau should have responsibility to communicate with trade, industry and investment bureau and environmental protection.

- The centralization and complexity of land delivery procedures delays in obtaining land access, investment and greatly open the room to intermediaries to get the land by high transaction costs. The city governments and land management and development bureau should improve the land delivery system of transparency, efficiency, and equity to retain the potential developers. In addition, the city government should earlier check and prepare the available land for the specific manufacturing sector. Trade, industry and investment bureau should the land development assessment, action plan, and request the land administration to prepare the land for the right developers. There is also a need to prepare a guideline and project appraisal before delivering the land to developers.

- Investment office should update and upgrade the earlier investment profile. And also there is a need to assess the additional potential resource base for manufacturers. The feasibility study should be done by highly qualified experts in this field that helps to disseminate the resource potential an effective and efficient way.

- City government and Electricity House should resolve the power shortage and interruption on manufacturing industries by establishing a power management system, and industrial control system networks to enhance the productivity of manufacturing firms.

- The municipality must construct a sewerage system around an industrial site to protect the environment from pollution. There is a great contribution to land development.

- The manufacturing firms must make treatment before releasing the wastes to enter into stream and recycling, purifying the wastewater and materials.

- The government should construct industrial roads inside manufacturing firms (industrial, and hamdil village), which has a significant impact on economic growth and transformation. On the other hand, the government should initiate and promote a public-private partnership to construct the road inside the manufacturing firms.

- The city administration should seriously focus on industrial development in order to bring successful economic transformation. In addition, changing the organizational structures instruments and policies need to designed and put into practice for accelerating economic transformation.

- Technical, vocational and educational school and universities should prepare and train a new generation of workers excited for a career in the advanced manufacturing industry. Thus, many manufacturing firms that are expanding, and upgrading their buildings and technology that are not balancing their capital investment with human resource development to meet the new demands. The city administration 
should focus on human resource development to provide qualified experts and professional to manufacturers at a reasonable price.

- Manufacturing firms' owners should change the attitude of the community through promoting their product and communicating with communities and be aware of safety, efficiency, and quality of their product.

- Government and city administration should focus on large scale manufacturing in order to be more productive, efficient, and play a big role in city economic development. Thus, the manufacturing industry is a good place for improving the working culture of the community. On the other hand, manufacturing firms should create a good working environment to increase productivity, employee satisfaction, rewarding positive behaviours, working confidence and unity among workers. It has an impact on the overall personality of people who work in manufacturing firms.

- Expansion of illegal trade has a significant impact on manufacturing firms and regional economy. The government should develop strong institutional linkage, dissemination of information, strictly implementing and monitoring laws and regulation.

- The government should reduce the current lending interest rate from $11.5 \%$ into $7 \%$ to attract a large number of private investors, resulting in increased the inflow of investment, employment creation and quality life for residents.

- Dire Dawa environmental protection authority (DDEPA) should create awareness through seminars for manufacturing firms on how to prevent and reduce environmental pollution on the health of urban dwellers, animals, and ground waters. Besides, the government should enforce the manufacturing firms to conduct environmental impact assessment as a very crucial measure to check the environmental problems.

- The city government, DDEPA, and Trade, industry and investment bureau should need to enforce the manufacturing firms to prepare environmental management plans for their day to date activities. In addition, the government needs to develop new strategies on how to evaluate the quality of feasibility study in line with goes green environment before the investment license issued.

- The city government and Dire Dawa environmental protection authority should ensure that manufacturing industries are environmentally friendly to prevent the damages. And also the trade industry and investment bureau require its initiation to establish industrial network development to move sustainable industrialization.

- The city government should address the main causes of political fragmentation and need to mitigate its impacts on economic policy design and implementation. The city government should also stabilize the political environment by designing flexible economic policies to maintain regional economic growth.

- The city government and Trade, Industry and Investment Bureau should establish one-stop shops, data sharing, and standardization to reduce unnecessary bureaucratic red tape. The Dire Dawa city administration should reform and simplify administrative procedures cutting bureaucratic burden. Furthermore, ICTs and E-government should adopt and used to improve administration regulations, transparency, and accountability.

- The city government and labour association affairs should modify the employment laws and labour market to get a hard worker and qualified educational background persons.

- City government and Trade, Industry and Investment Bureau should reduce restrictive trade regulations and need to encourage the benefits market activity for manufacturing firms.

- Suggestions for Further Research

- The study also recommended the use of institutional factors, technological factors, marketing factors, entrepreneurial factors and managerial factors as a variable of private investment in the manufacturing industry. The research was restricted to the manufacturing sector. Further studies are encouraged to conduct another sector (agriculture, and service sector) and compare the findings.

\section{Reference}

AACCSA and DAB development Research and Training PLC (2014). An overview of the Ethiopian manufacturing sector, unpublished.

Abdelkader, M., Fisher, G., Fawzy, S., \& Atallah, G. (2017, August). Infant Industry Argument: Theoretical Framework and Current Opportunity for Adoption. In 3rd International Conference on Social Sciences Economics and Finance on 26th-27th August.

Adugna, A. A., Wedaj Gebremeskel A., and Getachew, T. E. (2015). Assessment of private investment in Tigray, Northern Ethiopia.Challenges and Opportunities in the Case of Manufacturing Sector: International Journal of Current Research, 7(01), 12210-12217.

Aggarwal, V. K., \& Evenett, S. J. (2014). Do WTO rules preclude industrial policy? Evidence from the global 
economic crisis.Business and Politics, 16(4), 481-509.

Al-Subaihi, A. A. (2003). Sample size determination.Influencing factors and calculation strategies for survey research.Saudi medical journal, 24(4), 323-330

Al-Tit, A. A. (2017). Factors affecting the organizational performance of manufacturing firms.International Journal of Engineering Business Management, 9, 1847979017712628.

Anyanwu, J. C. (2012). Why Does Foreign Direct Investment Go Where It Goes?: New Evidence From African Countries. Annals of Economics \& Finance, 13(2).

Asante, Y. (2000). Determinants of private investment behaviour in Ghana.

Azam, M., \& Ahmad, S. A. (2013). The effects of corruption on foreign direct investment inflows: some empirical evidence from less developed countries. Journal of Applied Sciences Research, 9(6), 3462-3467.

Baker, S. R., Bloom, N., \& Davis, S. J. (2016).Measuring economic policy uncertainty. The Quarterly Journal of Economics, 131(4), 1593-1636.

Bayai, I., \& Nyangara, D. (2013). An analysis of determinants of private investment in Zimbabwe for the period 2009-2011.

Borchert, I., Gootiiz, B., \& Mattoo, A. (2012).Policy barriers to international trade in services: evidence from a new database. The World Bank.

CBE (2014). Commercial Bank of Ethiopia annual report.

Cohen, M. A., \& Tubb, A. (2018). The impact of environmental regulation on firm and country competitiveness: A meta-analysis of the Porter hypothesis. Journal of the Association of Environmental and Resource Economists, 5(2), 371-399.

Creswell, J. W. (2009). Research designs: Qualitative, quantitative, and mixed methods approach. Thousand Oaks, CA, EE.UU.: Sage.

Creswell, J. W. 2014. Research Design: Qualitative, Quantitative and Mixed Methods Approaches, Los Angeles, London, New Delhi, Singapore, Washington DC, SAGE Publications.

CSA (2014) Statistical abstract Dire Dawa

Demirgunes, K. (2017). Capital Structure Choice and Firm Value: New Empirical Evidence from Asymmetric Causality Test. International Journal of Financial Research, 8(2), 75.

Duru, M. (2012).New challenges for industrial policy in Nigeria.Universal Journal of Management and Social Sciences, 2(7), 12-20.

Echandi, R., Krajcovicova, J., \& Qiang, C. Z. (2015). The impact of investment policy in a changing global economy: a review of the literature.

Eckelman, M. J., \& Sherman, J. (2016). Environmental impacts of the US health care system and effects on public health. PloS one, 11(6), e0157014.

Eklund, J. E. (2013). Theories of investment: a theoretical review with empirical applications. In Swedish Entrepreneurship Forum (p. 2).

Eze, O. R., \& Ogiji, F. O. (2014). Impact of fiscal policy on the manufacturing sector output in Nigeria: An error correction analysis. British Journal of Business and Management Research, 1(2), 31-54.

Fenta, K. (2014). Industry and Industrialization in Ethiopia: Policy Dynamics and Spatial Distributions. European Journal of Business and Management, 6(34), 326-344.

Fiestas, I., \& Sinha, S. (2011). Constraints to private investment in the poorest developing countries-A review of the literature. London, UK: Nathan Associates London.

Fisher, I. (1930). The theory of interest. New York, 43.

Ginevičius, R., \& Šimelytè, A. (2011). Government incentives directed towards foreign direct investment: a case of Central and Eastern Europe. Journal of Business Economics and Management, 12(3), 435-450.

Girma A. (2015). Determinants of Export Performance and Employment of Labor in Large and Medium Scale Manufacturing Industry of Ethiopia: An ARDL Cointegration Approach. Unpublished Master's Thesis, Addis Ababa University.

Hailu, D. B., \& Debele, F. (2015). The Effect of Monetary Policy on the Private Sector Investment in Ethiopia: ARDL Co-Integration Approach. Economics, 4(2), 22.

Hashem, T. N., \& Irshaidat, R. (2014). The influence of political-legal forces on Jordanian industrial exports in the private sector. International Journal of Marketing Studies, 6(1), 103.

Hayashi, F. (1982). Tobin's marginal q and average q: A neoclassical interpretation. Econometrica: Journal of the Econometric Society, 213-224.

Helhel, Y. (2015). Comparative Analysis of Financial Performance of Foreign and Domestic Banks in Georgia.International Journal of Finance and Accounting, 4(1), 52-59.

IEG, S. O. (2013). The spending increase is a double-edged sword. IEG Sponsorship Report.

Ihugba, O. A., Odii, A., \& Njoku, A. C. (2013).Challenges and prospects of entrepreneurship in Nigeria.Academic Journal of Interdisciplinary Studies, 2(5), 25.

Jensen, M. C., \& Meckling, W. H. (1976). Theory of the firm: Managerial behavior, agency costs, and ownership 
structure. Journal of financial economics, 3(4), 305-360.

Johnson, R. B., \& Onwuegbuzie, A. J. (2004). Mixed methods research: A research paradigm whose time has come. EducationalResearcher, 33(7), 14-26.

Jorgenson, D. W. (1963). Capital theory and investment behavior. The American Economic Review, 53(2), $247-$ 259.

Kalolo, J. F. (2015). Addressing the Tensions and Controversies towards Quality Science Education: A Pragmatic Approach. Issues in Social Science, 3(1), 97.

Keynes, J. M. (1936). The general theory of employment, investment, and money. London and New York quoted from https://sites. google. com/site/biblioeconomicus/KeynesJohnMaynard-TheGeneralTheoryOf Employment interest and money. pdf [Accessed 07 Jan 2014].

Kinda, M. T. (2014).The Quest for Non-Resource-Based FDI: Do Taxes Matter? (No. 14-15). International Monetary Fund.

Knoll, A. (2014). Bringing policy coherence for development into the post-2015 agenda-challenges and prospects. Maastricht: ECDPM (Discussion Paper No. 163).

Kothari, C. R. (2004). Research Methodology: Methods and techniques. New Age International.

Kumarasamy, D., \& Singh, P. (2018). Access to Finance, Financial Development and Firm Ability to Export: Experience from Asia-Pacific Countries. Asian Economic Journal, 32(1), 15-38.

Kurabachew Menber (2017). Public and private investment analysis in Ethiopia.Research Journal of Economics and Business Studies, 4(4).

Latake, P. T., Pawar, P., \& Ranveer, A. C. (2015).The greenhouse effect and its impacts on the environment.International Journal of Innovative Research and Creative Technology, 1(3), 333-337.

Leavy, P. (2017).Research design: Quantitative, qualitative, mixed methods, arts-based, and community-based participatory research approaches. Guilford Publications.

Lotfalipour, M. R., Ashena, M., \& Zabihi, M. (2013). Exchange rate impacts on investment of manufacturing sectors in Iran. Business and Economic Research, 3(2), 12-22.

Makinde, T. (2005). Problems of policy implementation in developing nations: The Nigerian experience. Journal of Social sciences, 11(1), 63-69.

Mark, J., \& Nwaiwu, J. N. (2015).Impact of the political environment on the business performance of multinational companies in Nigeria.African Research Review, 9(3), 1-10.

Marton, M., \& Paulová, I. (2010).Applying the theory of constraints in the course of process improvement. Research Papers Faculty of Materials Science and Technology the Slovak University of Technology, 18(29), 71-76.

Matar, A., \& Eneizan, B. M. (2018). Determinants of financial performance in the industrial firms: Evidence from Jordan. Asian Journal of Agricultural Extension, Economics \& Sociology, 22(1), 1-10.

Mayende, S. (2013). The effects of tax incentives on firm performance: Evidence from Uganda. J. Pol. \& L., 6, 95.

Minetti, R., \& Zhu, S. C. (2011). Credit constraints and firm export: Microeconomic evidence from Italy. Journal of International Economics, 83(2), 109-125.

MoFED. Annual reports and database.Ministry of Finance and economic development (MOFEC) 2014/15.

Morgan, D. L. (2014).Pragmatism as a paradigm for social research.Qualitative Inquiry, 20(8), 1045-1053.

Moses, K., Alhassan, F. and Sakaka A. (2014). The effect of the manufacturing industry on the environment: Case of Atonsu-Kaase_Ahinsan in the Ashante Region of Ghana. Journal of Physical and Natural Sciences, 1(1), 1-16.

Munongo, S., Akanbi, O. A., \& Robinson, Z. (2017). Do tax incentives matter for investment? A literature review.Business and Economic Horizons, 13(2), 152-168.

Nick A. O., \& Fipa, F., F. (2016). Challenges of policy implementation in Nigeria: A case of Monetization policy. International Journal of Social Sciences and Management Research, 2(1)

Njuru$^{1}$, S. G., Ombuki, C., Wawire, N., \& Okeri, S. (2013). Taxation and private investment: evidence for Kenya. Management, 2(11), 78-93.

Nwandu, E. (2016). Impact of Rising Interest Rate on the Performances of the Nigerian Manufacturing Sector.European Journal of Business and Management.ISSN, 2222-2839.

Obokoh, L. O., \& Goldman, G. (2016).Infrastructure deficiency and the performance of small and medium-sized enterprises in Nigeria's Liberalised Economy.Acta Commercii, 16(1), 1-10.

OECD (2015).Policy framework for investment.OECD Publishing, Paris.Oguntoke, O., Awanu, A. E., \& Annegarn, H. J. (2012).Impact of cement factory operations on air quality and human health in Ewekoro Local Government Area, South-Western Nigeria.International journal of environmental studies, 69(6), 934945.

Oguntoke, O., Awanu, A. E., \& Annegarn, H. J. (2012).Impact of cement factory operations on air quality and human health in Ewekoro Local Government Area, South-Western Nigeria.International journal of 
environmental studies, 69(6), 934-945.

Osemeke, M. (2011).Problems and prospects of private sector organizations in Nigeria.International Journal of Business and Management, 6(4), 178.

Oulton, N. (1981). Aggregate investment and Tobin's Q: the evidence from Britain. Oxford Economic Papers, $33(2), 177-202$.

Pierre and Wondweson (2016).Assessment of the Environmental Pollution and its Impact on Economic Cooperation and Integration Initiatives of the IGAD Region.CONSORTIUM SAFEGE FWC-LOT 6.

Rahman, S. U. (1998). Theory of constraints: a review of the philosophy and its applications. International Journal of Operations \& Production Management, 18(4), 336-355.

Reppen, S. (2015). Finding Obstacles to Growth: Is Infrastructure a Binding Constraint on African Lightmanufacturing Firms?.International Journal of Economics and Financial Issues, 5(3), 820-832.

Root, F. R., \& Ahmed, A. A. (1978). The influence of policy instruments on manufacturing direct foreign investment in developing countries. Journal of International Business Studies, 9(3), 81-94.

Saarani, A. N., \& Shahadan, F. (2013). The comparison of capital structure determinants between Small And Medium Enterprises (SMEs) and large firms in Malaysia. International Journal of Economics and Finance Studies, 5(1), 22-32.

Schoonenboom, J., \& Johnson, R. B. (2017).How to Construct a Mixed Methods Research DesignWie man in Mixed Methods-Forschungs-Design konstruiert.KZfSS Kölner Zeitschrift für Soziologie und Sozialpsychologie, 69(2), 107-131.

Serrasqueiro, Z., \& Caetano, A. (2015). Trade-Off Theory versus Pecking Order Theory: capital structure decisions in a peripheral region of Portugal. Journal of Business Economics and Management, 16(2), 445466.

Shiferaw, A. (2017). Productive Capacity and Economic Growth in Ethiopia.UNDP CDP Background Paper, 34, 24.

Tasneem, F., Hamza, S. M., \& Basit, A.The Impact of Environmental Reporting on Firms’ Performance.

Tekeba E. (2018). Ethiopia's manufacturing industry opportunities, challenges and way forward. A sectorial overview: Novel Techniques in Nutrition and Food Science, 2(2) 1-7

Uwuigbe, U., Uwuigbe, O. R., Adeyemo, K. A., \& Anowai, N. C. (2016).Tax incentives and the growth of manufacturing firms in Nigeria. The Social Sciences, 11(7), 1338-1342.

Vernon, R. (1992). International investment and international trade in the product cycle. In International Economic Policies and their Theoretical Foundations (Second Edition) (pp. 415-435).

WAMIORI, G. M., Sakwa, M., \& Namusonge, G. S. (2016).Effect of access to finance on the financial performance of manufacturing firms in Kenya. Strategic Journal of Business \& Change Management, 3(4).

Wangwe, S., Mmari, D., Aikaeli, J., Rutatina, N., Mboghoina, T., \& Kinyondo, A. (2014).The performance of the manufacturing sector in Tanzania: Challenges and the way forward (No. 2014/085). WIDER Working Paper.

Wegrich, K., \& Jann, W. (2006).Theories of the policy cycle.In Handbook of public policy analysis (pp. 6988). Routledge.

Windle, P. E. (2010). Secondary data analysis: Is it useful and valid?.Journal of PeriAnesthesia Nursing, 25(5), $322-324$

Winter, S. (1990). Integrating implementation research. Implementation and the policy process (pp. 1938).Greenwood Press.

Worika, I. L., \& Umofia, N. (2017).The Impact of Infrastructural Development on Nigeria's Industrial Sector. African Research Review, 11(3), 23-30.

World Bank (2005).A better investment climate for everyone: World development report, 2005. A co-publication of the World Bank and Oxford University press 1-288, Washington DC.

World Bank (2015).Doing business 2015. Going beyond efficiency. Washington, DC. World Bank

Zariyawati, M. A., Hirnissa, M. T., \& Diana-Rose, F. (2017).WORKING CAPITAL MANAGEMENT AND FIRM PERFORMANCE OF SMALL AND LARGE FIRMS IN MALAYSIA.Journal of Global Business and Social Entrepreneurship (GBSE), 3(7). 